\title{
Informality and the Labor Market effects of Financial Crises
}

\author{
Emilio Colombo* \\ Università Cattolica del Sacro Cuore \\ Lorenzo Menna ${ }^{\dagger}$ \\ Banco de Mexico \\ Patrizio Tirelli ${ }^{\ddagger}$ \\ University of Milan Bicocca and \\ Griffith University
}

\begin{abstract}
We provide evidence, based on a large sample of countries, on the effects of financial crises on key labor market indicators, including official and unofficial employment, unemployment and the participation rate. Crises are followed by a drop in the official market participation rate and by an increase in informal employment. These responses are strongly persistent. Empirical results are then interpreted with a DSGE model which accounts for informality and for financial and labor market frictions. In this framework the informal sector acts as a buffer which absorbs workers in bad times and vice versa. Our simulations suggest the informal sector also is a crisis amplifier for the official economy. For a given financial shock, the ensuing contraction in the official economy is deeper and more persistent the larger the initial size of the unofficial sector. This implies that in less developed economies financial crises cause a relatively stronger reallocation of inputs towards less efficient sectors, expose a larger fraction of the population to the adverse effects of informality, cause a sharper deterioration of public finances limiting governments ability to supply public goods and to engage in countercyclical fiscal policies.
\end{abstract}

Keywords: Financial crises, Informal Economy, labor market frictions, endogenous participation

JEL codes: E26, E32, G01.

\footnotetext{
${ }^{*}$ Corresponding author, Email: emilio.colombo@unicatt.it. We thank seminar participants at Royal Holloway University, Cardiff University, Rethymno (ICMAIF Conference) for useful comments. We thank Davide Furceri for sharing Stata codes.

${ }^{\dagger}$ Email: lorenzo.menna@banxico.org.mx. The views expressed are those of the individual author and do not necessarily reflect official positions of the Banco de Mexico.

${ }^{\ddagger}$ Email: patrizio.tirelli@unimib.it
} 


\section{Introduction}

This paper investigates the effects of financial crises on labor reallocation between the official and informal sectors of the economy. We document the hitherto unexplored empirical response of the official participation rates to crises. To rationalize these results we build a new DSGE model that accounts for non-trivial banking sector, for an informal sector and for labor market flows.

A novel contribution of the paper is that we offer a perspective on why financial crises are "different" (Claessens, Kose, and Terrones, 2009) and produce deeper and more persistent contractions, as opposed for instance, to recessions induced by monetary contractions. In fact financial crises should be seen as large asymmetric shocks that cause a strong reallocation of inputs from the official to the unofficial sector. By contrast, monetary contractions are symmetrical shocks that affect consumption and savings decisions.

Financial crises tend to disrupt economic activity with a size and depth that is larger than standard economic recessions (Rajan and Zingales, 1998; Kroszner, Laeven, and Klingebiel, 2007; Cerra and Saxena, 2008; Dell'Ariccia, Detragiache, and Rajan, 2008; Reinhart and Rogoff, 2009) and empirical evidence suggests they act as a large asymmetric shock leading to a strong reallocation of economic activity between the official and the informal sectors of the economy (Colombo, Onnis, and Tirelli, 2016). This supports the view that financial crises might have important and hitherto unexplored implications for the labor market, i.e. for the official participation rate and for the informal labor market. The issue is potentially quite relevant because in developing (developed) countries the informal sector has been estimated to be around 36\% (13\%) of GDP over the 1999-2007 period (Schneider, Buehn, and Montenegro, 2010).

Unfortunately, direct evidence of informal labor markets is scarce, even though some studies suggest that in developing countries informal employment can be as high as $70 \%$ of total employment (Bosch and Esteban-Pretel, 2012). The ILO-KILM dataset has collected and organized available estimates on informal employment, measured through surveys either at household or at establishment level, but such information is available only for a few countries. As prima facie evidence Figure 1 shows that financial crises were associated with an increase in informal employment for all the episodes of banking crises included in the ILO-KILM dataset. More data are available concerning the official participation rate and for the share of self- 
employed workers, often used as a rough-and-ready proxy for informal employment (Loayza and Rigolini, 2011). ${ }^{1}$

\section{FIGURE 1 ABOUT HERE}

Based on a large panel of countries, our empirical analysis shows that financial crises are followed by a drop in output and investment, and by a rise in unemployment. This outcome is associated with a reduction in the participation rate and to an increase in the share of self-employed workers. Important differences emerge between the labor market responses of high-income and less-developed economies. High-income economies are characterized by a relatively stronger increase in unemployment, whereas in less developed economies we observe a larger fall in the official participation rate and a more pronounced increase in the self-employment rate.

To rationalize these results we build a DSGE model which accounts for both the official and the informal economy sectors, and incorporates banking frictions defined as in Gertler and Karadi (2011). The official labor market is characterized by search and matching frictions and we model both the intensive and extensive margin in the labor market. In our framework the official labor market participation rate is endogenous and driven by an optimal choice between being employed in the informal economy and searching for a job in the official sector. To the best of our knowledge this is the first paper that incorporates all these features in a dynamic general equilibrium framework.

Our results in a nutshell. The financial crisis, modeled as a shock to the net worth of bankers, raises the cost of capital for official firms and generates a drastic contraction in investment which is associated with a large and persistent fall in official output. The contraction in official economic activity induces firms to post fewer vacancies, and therefore causes an increase in unemployment. The central bank decision to lower interest rates dampens the contraction in the official sector and unambiguously stimulates demand in the informal sector. As a result, we observe a drop in the official participation rate and a prolonged expansion in informal economic activity and employment. In this regard the informal economy sector acts as a buffer which absorbs workers in bad times and vice versa. However, our simulations suggest the informal sector also is a crisis amplifier for the official economy. In fact, 
for a given financial shock, the fall in the official participation rate and the increase in unofficial employment are stronger and more persistent the larger is the size of the unofficial sector. This crucial new result is determined by a relatively simple and straightforward mechanism. The labor force reallocation is driven by an arbitrage condition that relates the value of seeking for a a job in the official economy to the value of working in the informal sector, which in turn is determined by the labor income in the informal economy. Therefore, the larger the size of the informal sector the greater is the employment reallocation to the unofficial sector which is necessary to bring informal labor incomes in line with the new value of a formal job. The model also predicts the relatively weaker increase in unemployment we estimate for less developed economies.

We contribute to an empirical literature concerned with the effects of financial crises on developing economies. Previous cross country studies investigate the consequences of financial crises on unemployment (Bernal-Verdugo, Furceri, and Guillaume, 2013), on the protection of collective labor rights (Blanton, Blanton, and Peksen, 2015) and on government policy responses (Ha and Kang, 2015). None of these contributions is concerned with the responses of the official participation rate and of informal employment to crises.

Our theoretical approach adds to recent developments in the literature on business cycles in developing countries, where accounting for informality allows to rationalize the relatively large output volatility and the excess relative volatility of consumption to output observed in these countries (Horvath, 2017; Restrepo-Echavarria, 2014). The paper also adds to Garcia-Cicco, Pancrazi, and Uribe (2010), who show that financial frictions are important to explain business cycles in emerging markets.

Our reading of the twofold role of the informal sector is in line with the findings in Fernández and Meza (2015) but in their contribution the key transmission channel is the degree of substitutability between formal and informal goods in the consumption bundle. Here we emphasize the specific role played by the labor market. In this regard our work contributes to a strand of literature which sees informality as driven by voluntary decisions to exit the official labor market, and where labor market frictions play a key role (Zenou, 2008; Ulyssea, 2010; Bosch and Esteban-Pretel, 2015; Meghir, Narita, and Robin, 2015)

The remainder of the paper is structured as follows: section 2 presents the empirical evidence, section 3 describes the model, section 4 presents the results, section 
5 concludes. The technical details of the model and the empirical section are relegated to the Appendix.

\section{Empirical evidence}

\subsection{Data}

Defining banking crises is often controversial, due to the lack of a consensual definition and the need of a certain degree of discretionary judgment. We adopt the well known classification by Laeven and Valencia (2010), who focus on systemic banking crises excluding distress events that affected isolated banks. Our choice is justified by the widespread use of this classification in the empirical literature.

Standard macroeconomic variables such as GDP and Investment are taken from the World Bank World Development Indicators and cover most countries from 1970 to 2015. It is well known that comprehensive and consistent labour market data are not available for all countries. We therefore obtain data on the labor market official participation rate, ${ }^{2}$ on the unemployment rate and on official employment from two datasets. The first one is the ILO-KILM dataset which covers 170 countries starting for the period $1990-2015 .{ }^{3}$ The second dataset is the OECD labor market statistics, available only for OECD countries but with longer time series, as for most countries it dates back to 1970.

In the Appendix we provide tables that report the main summary statistics for each variable and the list of countries contained in each dataset.

Following an established practice in the field, (Fiess, Fugazza, and Maloney, 2010; Loayza and Rigolini, 2011) we use data on self-employment as a proxy for the cyclical pattern of informal employment. As pointed out in La Porta and Shleifer (2008) selfemployment is likely to under-represent informal employment because it does not include unpaid family workers whose contribution to informal production is probably high, and informal firms led by self-employed entrepreneurs on average employ more than one worker. However Loayza and Rigolini (2011) document a strong correlation between the self-employment share and Schneider's Shadow Economy Index. ${ }^{4}$ Further, they document a strong correlation between the self-employment share and widely used indicators of informality such as the limited diffusion of retirement pension plans, formal job contract recognition, health insurance coverage. 
Fernández and Meza (2015) show in their cross-country study ${ }^{5}$ that a higher self employment share is associated with a lower procyclicality and a lower volatility of employment. As self employment may be more strongly related to informal employment in developing than in developed countries, we therefore present separate estimates for high- and non-high income countries.

In order to provide a more complete picture of the informal economy we include also measures of informal economic activity. It is well known that there is not a direct way of measuring the size of the informal economy; all estimation attempts need to follow an indirect approach. We use three different measures from Medina and Schneider (2018) who estimate the informal economy using a rich structural equation model, Elgin and Oztunali (2012) who use a calibrated DSGE model, and Colombo, Onnis, and Tirelli (2016) who use the Total Modified Electricity approach.

\subsection{Methodology}

Following Romer and Romer (1989); Cerra and Saxena (2008); Colombo, Onnis, and Tirelli (2016), we estimate the following autoregressive model:

$$
Y_{i, t}=\alpha_{i}+\sum_{s=1}^{3} \beta Y_{i, t-s}+\sum_{s=0}^{3} \gamma D B C_{i, t-s}+\epsilon_{i, t}
$$

where $Y_{i, t}$ is the growth rate of the variable of interest (participation rate, unemployment rate, self-employment rate, GDP, Investment) in country $i$ at time $t$, $D B C$ is a dummy variable for the presence of a banking crisis. Variables are defined as growth rates given their non stationarity, ${ }^{6}$ equation (1) is estimated with system GMM (Blundell and Bond, 1998) and then impulse response functions are calculated. We include time dummies to check whether crises reflect any other global shock. ${ }^{7}$ Our selection of the number of lags has been based on the fact that the KILM database is limited to 1990-2015 and we did not want to loose valuable information by estimating the model with many lags. However our results are robust to the number of lags of both the dependent variable and the banking crisis dummy. ${ }^{8}$ The Appendix reports additional robustness checks, including Panel VAR estimates where we have analyzed the joint response of the participation rate and of GDP to a banking crisis. The Appendix also contains the tables underlying the impulse response functions. 


\subsection{Results}

Figure 2 shows the impulse response functions of GDP and Investment to crisis episodes. They broadly match previous results (Cerra and Saxena, 2008; Colombo, Onnis, and Tirelli, 2016): we observe a large drop in both variables, which appears to be stronger for developed economies. Figure 6 reports IRFs of the effect of banking crisis on different measures of informal economy; all measures show that informal economic activity rises following financial crises.

Figures 3-5 show impulse responses for labor market variables. Irrespective of the database used, banking crises are associated with a reduction in the official participation rate, in official employment and to an increase in the unemployment rate. Important differences are detected between high income countries and the rest of the sample, where the latter is apparently characterized by a weaker increase in the unemployment rate and by a stronger fall in the participation rate. This latter result is complemented by the increase in the self employment ratio which appears to be significant only for the group of non high-income countries.

The finding of a persistent effect of banking crises on GDP is not new in the literature. Indeed this was the major finding of the path breaking study by Cerra and Saxena (2008). This result has been confirmed by subsequent studies. For example Furceri and Zdzienicka (2012) show that banking crises are associated with a permanent output loss in a large sample of countries. Their estimates are very much similar to ours as they find GDP to be $4 \%$ lower 8 years after the crisis. Sizable long lasting effects of banking crises on GDP have been found by da Rocha and Solomou (2015) during the interwar period and by Furceri and Mourougane (2012) on potential output. What could be considered more puzzling is the effect on the labour market given that some degree of wage flexibility should induce a certain degree of adjustment following a shock. However also in this case the empirical literature has findings which are in line with ours: Bernal-Verdugo, Furceri, and Guillaume (2013) show that banking crises have large and long lasting effects on the labor market and on unemployment. Similar results are obtained by Boeri, Garibaldi, and Moen (2013) and by Calvo, Coricelli, and Ottonello (2012).

A word of caution is needed on the empirical measurement of the persistence of crisis shocks. This is a common problem in estimating autoregressive models with highly persistent series such as standard macroeconomic ones and is essen- 
tially a power problem of statistical tests. Unfortunately in order to fully address this issue we would need a large sample size along the time dimension while our panel is indeed large but mostly along the cross sectional dimension.

\section{FIGURE 2, 3, 4, 5, 6 ABOUT HERE}

\section{$3 \quad$ The model $^{9}$}

Our model accounts for both the official $(o)$ and the informal $(s)$ economy. Following Fernández and Meza (2015) and Restrepo-Echavarria (2014), to motivate the existence of an informal sector we assume that the households' consumption bundle, $c$, is:

$$
c_{t}=\left[\left(1-\alpha_{c}\right)^{\frac{1}{\varepsilon}}\left(c_{t}^{o}\right)^{\frac{\varepsilon-1}{\varepsilon}}+\left(\alpha_{c}\right)^{\frac{1}{\varepsilon}}\left(c_{t}^{s}\right)^{\frac{\epsilon-1}{\varepsilon}}\right]^{\frac{\varepsilon}{\varepsilon-1}}
$$

where $\alpha_{c}$ is crucial to calibrate the relative size of the informal economy in steady state. The existence of the informal sector could be also motivated by tax distortions; in an earlier version we incorporated tax distortions to obtain the same relative share of the informal sector (in this case the value of $\alpha_{c}$ was negligible). Our simulation results were not affected by these different modelling choices. Household have Dixit-Stiglitz preferences over the goods produced in sector $j$ of the economy. It follows that demand functions for individual goods within each consumption bundle are:

$$
c_{t}\left(z^{j}\right)=\left(\frac{P_{t}^{R j}\left(z^{j}\right)}{P_{t}^{R j}}\right)^{-\sigma^{j}} c_{t}^{j}
$$

where $\frac{P_{t}^{R j}\left(z^{j}\right)}{P_{t}^{R j}}$ is firm $z^{j}$ relative retail price. Demand functions for the sectoral consumption bundles are:

$$
\begin{gathered}
c_{t}^{o}=\left(1-\alpha_{c}\right)\left(\frac{P_{t}^{R, o}}{P_{t}}\right)^{-\varepsilon} c_{t} \\
c_{t}^{s}=\alpha_{c}\left(\frac{P_{t}^{R, s}}{P_{t}}\right)^{-\varepsilon} c_{t}
\end{gathered}
$$

where $\frac{P_{t}^{R, j}}{P_{t}}$ is the relative sectoral price. 
Our assumption that firms populate the informal economy follows La Porta and Shleifer (2008) whose cross-country analysis of informality is based on large World Bank surveys where $85 \%$ of informal firms have at least two employees in addition to the owner. ${ }^{10}$ Our characterization of the informal economy is consistent with a well-known "stylized fact": firms operating in this sector have access to a relatively more labor intensive production technology (Amaral and Quintin, 2006; Koreshkova, 2006). Finally, we do not model financial frictions in the informal sector and, following Koreshkova (2006), we assume that households directly finance unofficial firms. Indeed La Porta and Shleifer (2008) report that about 75 percent of informal firms investments were with internal funds and 10.5 percent with help from the owner's family, suggesting that household financing is crucial for informal firms. Our characterization of informal firms neglects the role of retained profits and emphasizes the alternatives faced by households. In fact they can either finance informal firms or hold deposit at commercial banks, which are modeled as in Gertler and Karadi (2011).

In both sectors perfectly competitive firms produce wholesale goods which are then sold to monopolistically competitive retail firms that are subject to price adjustment costs.

\subsection{Households}

There is a continuum of households of measure $i \in(0,1)$. Each household incorporates a continuum of individuals, $l$ workers and $(1-l)$ bankers. Households preferences are defined by:

$$
U_{t}=E_{t} \sum_{k=o}^{\infty} \beta^{k}\left\{\ln \left(c_{t+k}^{i}-b c_{t+k-1}\right)-\left(\frac{\chi\left(h_{t+k}^{i}\right)^{1+\phi} l_{t+k}^{i, o}}{1+\phi}\right)\right\}
$$

where $c^{i}$ is individual consumption, $b$ defines consumption habits and $l^{i}$ and $h_{t}^{i}$ respectively are the number of employed individuals and their labor effort in the official and informal economy sectors. ${ }^{11}$

Following Zenou (2008) the labor market is characterized by search frictions in the official sector and by perfect competition in the unofficial sector. ${ }^{12}$ Official sector employees earn a product real wage $w_{t}^{o}$. Individuals who are not hired in the official sector either take official sector unemployment status, or work in the unofficial sector. Unemployed individuals search for next-period hire in the official 
sector, therefore only unemployed individuals can enter a new match with an employer in the official sector. Unofficial sector employees earn the product real wage $w_{t}^{s}$. Following earlier contributions (Merz, 1995; Andolfatto, 1996), we assume that household members perfectly share the risk of sectoral employment and unemployment outcomes. Thus, individual consumption decisions are the same irrespective of the individual labor market status.

The representative household flow budget constraint is:

$$
\begin{aligned}
& c_{t}+\frac{P_{t}^{R, o}}{P_{t}} D_{t}+\frac{P_{t}^{R, s}}{P_{t}} I_{t}^{s}= \\
= & \frac{P_{t}^{R, o}}{P_{t}} w_{t}^{o} h^{o} l_{t}^{o}+\frac{P_{t}^{R, o}}{P_{t}} R_{t-1}^{D} D_{t-1} \\
& +\frac{P_{t}^{R, s}}{P_{t}} w_{t}^{s} h^{s} l_{t}^{s}+\frac{P_{t}^{R, s}}{P_{t}}\left(r_{t}^{k, s}-\delta\right) k_{t-1}^{s}+\frac{P_{t}^{R, o}}{P_{t}} \Pi_{t}^{o}+\frac{P_{t}^{R, s}}{P_{t}} \Pi_{t}^{s}
\end{aligned}
$$

where $D$ are bank deposits, which yield the rate of return $R_{t}^{D}, k^{s}$ and $I_{t}^{s}$ are the capital stock and the amount of investment in the informal sector, $r^{k, s}$ is the return from capital investment in the informal economy and $\delta$ is the capital depreciation rate. $\Pi^{o}$ and $\Pi^{s}$ define sectoral profits. ${ }^{13}$ Note that households choose investment in the informal sector, that is, accumulation of $k_{t}^{s}$ is driven by:

$$
k_{t}^{s}=(1-\delta) k_{t-1}^{s}+\left[1-S\left(\frac{I_{t}^{s}}{I_{t-1}^{s}}\right)\right] I_{t}^{s},
$$

where $S\left(\frac{I_{t}^{s}}{I_{t-1}^{s}}\right)$ defines investment ajustment costs, whereas official investment is chosen by official firms that borrow from banks.

\subsection{Labor market}

The labor market is characterized by search frictions in the official sector and by perfect competition in the unofficial sector as in Zenou (2008). Following Christiano, Trabandt, and Walentin (2011) and Zhang (2011), to facilitate model tractability we assume that employment agencies post vacancies in the official labor market at the official output cost $f_{p v}^{E A}$ and bargain with workers both the official sector product wage rate $w_{t}^{o}$ and the number of hours worked $h^{o}$. Subsequently they combine individual labor supplies into a labor input which is then transferred to official sector wholesale firms at the competitive price $P_{t}^{E A}$, defined in terms of official sector goods. New matches per unit of time are determined by a standard matching tech- 
nology:

$$
M_{t}=m\left(u_{t}\right)^{\varkappa}\left(V_{t}\right)^{1-\varkappa}
$$

where $V_{t}$ and $u_{t}$ respectively define the number of vacancies in the official sector and unemployment, and $m$ is a parameter that defines the efficiency of the matching technology. The probability that a vacancy $z_{t}^{V}$ be filled therefore is:

$$
z_{t}^{V}=\frac{M_{t}}{V_{t}}=m\left(\frac{u_{t}}{V_{t}}\right)^{\varkappa}
$$

Similarly, the probability that an unemployed individual gets a job in the official sector, $z_{t}^{u n}$, is:

$$
z_{t}^{u n}=\frac{M_{t}}{u_{t}}=m\left(\frac{V_{t}}{u_{t}}\right)^{1-\varkappa}
$$

Official employment follows the law of motion:

$$
l_{t}^{o}(s)=\rho^{s} l_{t-1}^{o}(s)+z_{t}^{V} V_{t}(s)
$$

where $\rho^{s}\left(0<\rho^{s}<1\right)$ defines the exogenous probability that a match survives up to next period and $z_{t}^{V} V_{t}=m\left(u_{t}\right)^{\varkappa}\left(V_{t}\right)^{1-\varkappa}$ defines new matches.

Employment agencies maximize discounted profits subject to (6), obtaining the following hiring condition:

$$
\frac{f_{p v}^{E A}}{z_{t}^{V}}=\left(P_{t}^{E A}-w_{t}^{o}\right) h_{t}^{o}+\beta \frac{\pi_{t+1}^{R, o} \lambda_{t+1}}{\pi_{t+1} \lambda_{t}} \frac{f_{p v}^{E A}}{z_{t+1}^{V}} \rho^{S}
$$

where $\frac{f_{p v}^{E A}}{z_{t}^{V}}$ defines the marginal cost of hiring a worker ${ }^{14}$ and the r.h.s. of (7) is the marginal benefit, including both the price margin $\left(P_{t}^{E A}-w_{t}^{o}\right)$, and the discounted savings on posting a future vacancy, which are proportional to the match survival rate $\rho^{s}$.

The nominal wage and the number of hours are negotiated by workers and employment agencies within a Nash bargaining framework. We assume simultaneous bargaining over $W$ and $h$.

The value of a new hire for the employment agency is:

$$
v_{t}^{E A}=\left(P_{t}^{E A}-w_{t}^{o}\right) h_{t}^{o}+\beta \frac{\pi_{t+1}^{R, o} \lambda_{t+1}}{\pi_{t+1} \lambda_{t}} v_{t+1}^{E A} \rho^{S}
$$

where $v_{t}^{E A}$ is defined in official goods. The conditions that define the value for an 
individual of being employed in the official sector and unemployed respectively are:

$$
\begin{gathered}
v_{t}^{l o}=\lambda_{t} \frac{P_{t}^{R, o}}{P_{t}} w_{t}^{o} h_{t}^{o}-\chi \frac{h_{t}^{o(1+\phi)}}{1+\phi}+\beta\left[\rho v_{t+1}^{l o}+(1-\rho) v_{t+1}^{u}\right] \\
v_{t}^{u}=\lambda_{t} \frac{P_{t}^{R, o}}{P_{t}} b^{u}+\beta\left[z_{t+1}^{u n} v_{t+1}^{l o}+\left(1-z_{t+1}^{u n}\right) v_{t+1}^{u}\right]
\end{gathered}
$$

where $b^{u}$ defines the value of being unemployed in period $t$. Bosch and EstebanPretel (2012) point out that this value may capture elements such as the value of leisure, unemployment benefits and home production, which they treat as distinct from informal employment. Note that the option value of being employed in the unofficial sector does not enter (8) and (9) because we impose the stock equilibrium condition:

$$
v_{t}^{u}=v_{t}^{s}
$$

where

$$
v_{t}^{s}=\lambda_{t} \frac{P_{t}^{R, s}}{P_{t}} w_{t}^{s} h_{t}^{s}-\chi_{t} \frac{h_{t}^{s(1+\phi)}}{1+\phi}+\beta v_{t+1}^{s}
$$

defines the value to the individual of being employed in the unofficial sector. This is equivalent to assume that the household decides how many members who are not employed in the official sector will search for an official job and how many will work in the informal sector. The optimal choice implies that in equilibrium expected returns from the two alternatives must be equal.

Our results crucially depend on the adjustments that (10) implies for $u_{t}$ and $l_{t}^{s} h_{t}^{s}$. For instance, a deterioration in the value of official employment calls for an increase in unemployment and a fall in $v_{t}^{u}$. This is turn, calls for an increase in labor supply in the unofficial sector, which is associated to a fall in $v_{t}^{s}$.

Wages and hours are set to maximize the product:

$$
\left(v_{t}^{E A}\right)^{1-\vartheta}\left(v_{t}^{l o}-v_{t}^{u}\right)^{\vartheta}
$$

where $\vartheta$ identifies the relative bargaining power of each party.

Condition (12) is maximized by the following two FOCs:

$$
w_{t}^{o} h_{t}^{o}=(1-\theta)\left(\chi \frac{h_{t}^{o(1+\phi)}}{\left(\frac{\lambda_{t} P_{t}^{R, o}}{P_{t}}\right)(1+\phi)}+b^{u}\right)+\theta\left\{P_{t}^{E A} h_{t}^{o}+\beta \frac{\lambda_{t+1} \pi_{t+1}^{R, o}}{\lambda_{t} \pi_{t+1}} z_{t+1}^{u n} v_{t+1}^{e a}\right\}
$$


and

$$
\chi h_{t}^{o(\phi)}=P_{t}^{E A}
$$

Finally, aggregating across households

$$
l=l_{t}^{o}+l_{t}^{u}+u_{t}
$$

\subsection{Banks}

Official banks collect deposits from households and lend funds to official wholesale firms, who use them to purchase capital goods. There is an exogenous probability $\sigma_{(1-l)}$ that bankers continue to perform their role in the following period. In turn, with probability $\left(1-\sigma_{(1-l)}\right)$ bankers exit the financial sector and become workers; therefore for each individual engaged in banking, activity is expected to last $\left(1-\sigma_{(1-l)}\right)^{-1}$ periods. ${ }^{15}$ Exiting bankers transfer their net worth to the household. The household provides new bankers with an initial endowment which is a fraction $\rho_{(1-l)}\left(1-\sigma_{(1-l)}\right)^{-1}$ of last period loans.

At the end of period $t$ the $j$ - th banker's balance sheet is given by:

$$
q_{t}^{o} L_{j, t}^{W}=\left(D_{j, t+1}+N W_{j, t}\right)\left(\frac{p_{t}^{o}}{p_{t}}\right)
$$

where $L_{j, t}^{W}$ is the amount of claims on firms, $q_{t}^{o}$ is their relative price in terms of the consumption bundle (2), and $N W_{j, t}$ is the banker net worth at the end of period $t$. Bankers' net worth and bank deposits are defined in official goods, whose relative price price in terms of the consumption bundle is $\frac{p^{o}}{p}$.

The banker charges a gross return $R_{t}^{W}$ on loans, and pays a gross real return $R_{t-1}^{D}$ on households deposits. At the beginning of each period the banker may choose to divert a fraction $\phi$ of available funds from the bank portfolio because, by assumption, $\phi$ defines the unit cost households must bear to recover diverted funds. To ensure that depositors are willing to supply funds to bankers the discounted continuation value of a banker should be no less than the value of divertible funds. In fact the supply of deposits sets a limit to the bankers' leverage ratio

$$
l e v_{t}=\frac{q_{t}^{o} L_{t}^{W}}{\left(\frac{p_{t}^{o}}{p_{t}}\right) N W_{t}}=\frac{\eta_{j, t}}{\phi-v_{j, t}^{k}}
$$


where $v_{t}^{k}$ is the expected discounted marginal gain to the banker of expanding loans by a unit (holding net worth constant); $\eta_{t}$ defines the expected discounted value of having another unit of net worth (holding assets constant). The leverage ratio allows bankers to earn a credit spread between earnings on loans and interests paid on liabilities which prevents bankers from diverting funds and induces them to accumulate wealth until they exits the market. The law of motion of the total net worth is:

$$
N W_{t}=\sigma_{(1-l)}\left\{\left(\left(R_{t}^{W}-R_{t-1}^{D}\right) l e v_{t-1}+R_{t-1}^{D}\right\} \frac{N W_{t-1}}{\exp \left(\xi_{t}^{o}\right)}+\varrho_{(1-l)} q_{t-1}^{o} L_{t-1}^{W}\right.
$$

where $\varrho_{(1-l)} q_{t-1}^{o} L_{t-1}^{W}$ defines net worth endowments for new-born bankers and $\xi_{t}^{o}$ is a i.i.d. net worth shock that initiates the crisis, as in Gertler and Karadi (2011).

\subsubsection{Official investment and capital accumulation}

At the beginning of each period official firms use funds borrowed from banks to finance their capital acquisition from capital goods producers to be used for production. After production, undepreciated capital is sold back to capital goods producers. At the end of each period capital goods producers,owned by households, purchase undepreciated capital from intermediate firms and obtain from retail firms the final goods devoted to investment in order to assemble the capital goods which are then sold to the wholesale firms. Capital accumulation is subject to:

$$
k_{t}^{o}=(1-\delta) k_{t-1}^{o}+\left[1-S\left(\frac{I_{t}^{o}}{I_{t-1}^{o}}\right)\right] I_{t}^{o}
$$

where

$$
S\left(\frac{I_{t}^{o}}{I_{t-1}^{o}}\right)=\frac{\gamma_{I}}{2}\left(\frac{I_{t}^{o}}{I_{t-1}^{o}}-1\right)^{2}
$$

defines investment adjustment costs.

\subsection{Monetary policy}

Monetary policy is assumed to follow a standard inflation-targeting rule with interestrate smoothing, where $i$ defines the steady state nominal interest rate 


$$
i_{t}=\left[i\left(\pi_{t}^{o}\right)^{\phi_{\pi}}\right]^{\rho_{i}}\left[i_{t-1}\right]^{1-\rho_{i}}
$$

and the link between the nominal and the real interest rates is given by a standard Fisher equation:

$$
1+i_{t}=R_{t+1}^{D} E_{t} \pi_{t+1}^{o}
$$

\section{Results}

We model a banking crisis by calibrating an adverse white noise shock to the bankers real net worth which causes an immediate $60 \%$ reduction of $N W_{t}$, broadly in line with the initial $N W_{t}$ fall reported in Gertler and Karadi's (2011) crisis experiment. Right from the outset, it is important to emphasize that our focus is different from theirs, as we aim at characterizing the role of the informal economy in shaping labor market outcomes, instead of matching GDP losses recorded in specific episodes such as the 2007 Great Financial Crisis. Figures 7, 8 report impulse response functions of the relevant variables. Simulation of the shock in the one-sector economy shows that after 5 quarters GDP falls by little less than $3 \%$ and slowly recovers thereafter. This happens in spite of the interest rate cuts implemented by the Central Bank. The contraction of investment follows the same time pattern but is much sharper, reaching a minimum at about $-20 \%$.

In the labor market the contraction triggers adjustment both in the intensive and in the extensive margin. Worked hours for employed individuals immediately fall. The contraction in official economic activity induces firms to post fewer vacancies, and therefore causes an increase in unemployment. Employment is gradually reduced and reaches a minimum at about $-2 \%$. These findings are broadly in line with recent theoretical studies (see for instance Toracchi, 2017).

The existence of an informal sector has important implications. Unemployed individuals now have an outside option - working in the informal sector - and the official labor market participation rate must ensure that condition $v_{t}^{u}=v_{t}^{s}$ holds. The policy of lower interest rates is an unambiguous demand stimulus for informal goods. If the participation rate remained constant, this would raise labor demand and real wages in the unofficial labor market, driving $v_{t}^{s}$ above $v_{t}^{u}$. Adjustment in the official market participation rate prevents this outcome, determining a labor reallocation towards the informal economy that eventually disciplines informal wages 
and allows an increase in informal employment and production. Note that the investment gaps in the two sectors have opposite signs and drive sectoral capital accumulations away from steady state and in opposite directions. As a result, informal (official) economic activity expands (contracts) for a prolonged period. Indeed, it takes a long time to reverse the accumulation of capital in the informal sector. This, in turn, contributes to the persistence of the official sector slump we observe in the two-sector model. Note that product wages fall in both sectors for different reasons. In the official sector it happens due to lower labor demand, whereas in the informal sector it happens because the inflow of workers raises the labor supply. As a result inflation falls in both sectors, and the diverging growth rates of sectoral products bring about only a limited fall in the official goods relative price.

The labor reallocation mechanism which determines our results is driven by the initial disalignment of incentives to supply labor in the two sectors. To support intuition, note that straightforward manipulation of (9) yields:

$$
\lambda_{t}\left(\frac{P_{t}^{R, s}}{P_{t}} w_{t}^{s} h_{t}^{s}-\frac{P_{t}^{R, o}}{P_{t}} b^{u}\right)-\chi_{t} \frac{h_{t}^{s(1+\phi)}}{1+\phi}=\beta z_{t+1}^{u n}\left[v_{t+1}^{l o}-v_{t+1}^{u}\right] .
$$

i.e., the welfare surplus from working at time $t$ in the informal sector, relative to being unemployed and searching for a job in the official sector next period, must equal the expected difference between the values for an individual of being employed in the official sector and being unemployed. The banking crisis unambiguously reduces the expected surplus from official employment, therefore workers reallocate towards the informal sector. The strength of the fall in the official employment and participation rates is essentially determined by the immediate adjustment in the informal capital/labor ratio which is necessary to adequately reduce informal wages.

The informal economy sector acts as a buffer which absorbs workers, and also as a crisis amplifier for the official economy. In fact, for a given financial shock, the ensuing contraction in official employment is stronger and more persistent when the size of the unofficial sector is larger. This occurs because, when $\frac{y^{s}}{y^{\circ}}$ is relatively large a greater labor reallocation is necessary to maintain (10) after the shock. This also explains why a large shadow economy is associated with a smaller increase in the unemployment rate. In fact, for any given official employment contraction the corresponding increase in unemployment is more limited the larger is the increase in $l_{t}^{s}$ which is necessary for $v_{t}^{u}=v_{t}^{s}$ to obtain. 


\section{FIGURE 7 ABOUT HERE}

\section{FIGURE 8 ABOUT HERE}

\subsection{The role of adjustment costs}

In the model there are two types of adjustment costs: one determines price stickiness and the other slows down the reaction of investments to the shock. Figure 9 shows that both frictions are important to obtain our results. When we remove price adjustment costs, price flexibility substantially dampens the fall (increase) in official (informal) GDP. As a consequence there is a weaker increase in informal employment and the unemployment response to the shock is essentially nil.

The model ability to match labor market variables drastically deteriorates when we remove both price and investment adjustment costs. In fact, capital producers front load the fall in investment, which then monotonically recovers at a relatively rapid pace.

The immediate reduction in the capital stock is associated with a dramatic fall in demand for official labor, in the number of vacancies and in the consumption wage paid by official firms. The initial disalignment between $v_{t}^{u}$ and $v_{t}^{s}$ calls for a massive relocation of workers to the informal sector, which is much stronger than in our benchmark case, and determines a counterfactual immediate reduction in unemployment. However, this outcome is short-lived, because the official investment recovery also drives up official employment. In spite of the deeper initial contraction, the model without adjustment cost tends to underestimate the persistent effects of the shocks both in the goods sector and in the labor market.

FIGURE 9 ABOUT HERE 


\subsection{The monetary policy response}

In principle, a stronger interest rate response to the crisis might limit the adverse effects of the shock. To identify the stabilization potential of monetary policy we experiment with a stronger interest rate feedback on inflation, which is raised from 1.5 to an implausibly large value of five, implying that a $1 \%$ drop in inflation lowers the interest rate by $5 \%$. Simulation results are reported in Figure 10 , The recession is unambiguously dampened, but the crisis effects remain very persistent and there is still a substantial drop in the participation rate. This happens because the interest rate fall adds a stimulus to demand for informal goods which inflates the informal sector. As a result the incentives to sectoral relocation of inputs remain strong and the post-crisis recovery remains very slow.

\section{FIGURE 10 ABOUT HERE}

\subsection{Assuming search frictions in the unofficial sector}

We have developed an alternative labor market characterization where matching frictions apply to both labor markets, and unemployed individuals seek for a job either in the official or in the unofficial market. To sharpen potential differences relative to the case of a fully competitive informal labor market we have imposed that matching frictions are identical in the official and unofficial labor markets. Also note that it is very difficult to calibrate unofficial labor market frictions due to lack of data on unofficial vacancies and on unemployed individuals who search in the unofficial labor market. This prevents any meaningful calibration of labor market tightness $\left(\frac{v^{s}}{u^{s}}\right)$ in the unofficial economy. A number of results (Figure 11) are fully consistent with those obtained under a fully competitive unofficial labor market. The crisis still generates a contraction (expansion) in the official (unofficial) goods market. Unemployment increases and the official labor market participation rate falls. When the share of the informal sector is smaller, the increase in unemployment is stronger and the fall in the official labor market participation rate is smaller.

The only difference with our benchmark model is that the adjustments in both output and employment are not affected by the informal sector share. This latter 
result can be rationalized as follows. When the unofficial labor market is competitive, the sectoral reallocation of workers, driven by the unofficial labor productivity, is entirely absorbed by unofficial employment. Therefore it takes a relatively strong employment/output reallocation to reach the new equilibrium if the shadow economy is large. In the new environment, employment agencies drive a wedge between labor productivity and the real wage. As a result the labor supply expansion is weaker for any given increase in the number of individuals seeking for a job in the unofficial sector. As a result, part of the workers reallocation is absorbed by the increase in unofficial unemployment. In fact it is the unemployment reallocation that ensures labor market equilibrium: the number of unemployed individuals that search in the official labor market initially falls dramatically irrespective of the size of the informal sector. We regard the assumption of identical sectoral labor market structures as an extreme case. In fact Zenou (2008) forcefully argues that matching frictions are at best of very limited importance in the unofficial sector. In addition, it seems difficult to assign significant bargaining power to unofficial workers. We therefore suggest that the assumption of competitive unofficial labor markets should be preferred.

\section{FIGURE 11 ABOUT HERE}

\section{Conclusions}

Our empirical analysis, based on a large sample of countries, suggests that financial crises are followed by a drop in the official market participation rate and by an increase in informal employment.

To rationalize the evidence we analyze the labor market response in a two sector DSGE model that accounts for financial and labor market frictions. In our framework the official labor market participation rate is endogenous and driven by an optimal choice between being employed in the informal economy and searching for a job in the official sector. To the best of our knowledge this is the first paper that incorporates all these features in a dynamic general equilibrium framework.

The financial crisis raises the cost of capital for official firms and generates a drastic contraction in investment which is associated to a large and persistent fall 
in official output. This causes a large reallocation effect of employment from the official to the informal economy, associated to an increase in unemployment and a to a lower participation rate in the formal labor market. The informal sector therefore acts as a buffer which absorbs workers in bad times and vice-versa. For a given financial shock, the ensuing contraction in the official economy is deeper and more persistent the larger the initial size of the unofficial sector. These results imply that in less developed economies financial crises cause a relatively stronger reallocation of inputs towards less efficient sectors, expose a larger fraction of the population to the adverse effects of informality, i.e. limited ability to manage individual income shocks, cause a sharper deterioration of public finances limiting governments ability to supply public goods and to engage in counteryclical fiscal policies.

We also find that strengthening the interest rate response to the initial shock has limited stabilizing effects. Essentially this happens because the crisis is an asymmetric shock, whereas the interest rate policy has symmetrical effects on sectoral demands. Thus fiscal policy might play a useful role.

Demand stabilization policies, aimed at limiting the initial surge in layoffs, could lower the consumption tax rate and increase public consumption, which is by definition restricted to official goods.

On the supply side, there is little doubt that lowering taxation on factor incomes would limit the sectoral reallocation. Further, employment subsidies should facilitate the official sector recovery. Fiscal policy design requires a careful analysis of the specific, and hitherto largely unexplored, welfare implications that financial crises have in countries characterized by large informal sectors. We leave this for future research. 


\section{References}

Amaral, Pedro S. and Erwan Quintin. 2006. "A competitive model of the informal sector.” Journal of Monetary Economics 53 (7):1541-1553.

Andolfatto, David. 1996. “Business Cycles and Labor-Market Search.” American Economic Review 86 (1):112-32.

Bernal-Verdugo, Lorenzo E., Davide Furceri, and Dominique Guillaume. 2013. "Banking crises, labor reforms, and unemployment." Journal of Comparative Economics 41 (4):1202 - 1219.

Blanton, Robert G., Shannon Lindsey Blanton, and Dursun Peksen. 2015. "Financial Crises and Labor: Does Tight Money Loosen Labor Rights?" World Development $76: 1-12$.

Blundell, Richard and Stephen Bond. 1998. "Initial conditions and moment restrictions in dynamic panel data models.” Journal of Econometrics 87 (1):115-143.

Boeri, Tito, Pietro Garibaldi, and Espen Moen. 2013. "Financial Shocks and Labor: Facts and Theories.” IMF Economic Review 61 (4):631663.

Bosch, Mariano and Julen Esteban-Pretel. 2012. "Job creation and job destruction in the presence of informal markets.” Journal of Development Economics 98 (2):270286.

- 2015. "The labor market effects of introducing unemployment benefits in an economy with high informality." European Economic Review 75 (C):1-17.

Boz, Emine, C. Bora Durdu, and Nan Li. 2015. "Emerging Market Business Cycles: The Role of Labor Market Frictions." Journal of Money, Credit and Banking $47(1): 31-72$.

Calvo, Guillermo A, Fabrizio Coricelli, and Pablo Ottonello. 2012. "Labor Market, Financial Crises and Inflation: Jobless and Wageless Recoveries.” Working Paper 18480, National Bureau of Economic Research.

Cerra, Valerie and Sweta Saxena. 2008. "Growth Dynamics: The Myth of Economic Recovery." American Economic Review 98 (1):439-57. 
Christiano, Lawrence J., Mathias Trabandt, and Karl Walentin. 2011. "Introducing financial frictions and unemployment into a small open economy model." Journal of Economic Dynamics and Control 35 (12):1999-2041.

Claessens, Stijn, M. Ayhan Kose, and Marco E. Terrones. 2009. "What happens during recessions, crunches and busts?” Economic Policy 24:653-700.

Colgiago, Andrea and Lorenza Rossi. 2014. "Firm entry, endogenous markups and the dynamics of the labor share of income." Macroeconomic Dynamics forthcoming.

Colombo, Emilio, Luisanna Onnis, and Patrizio Tirelli. 2016. “Shadow economies at times of banking crises: Empirics and theory." Journal of Banking \& Finance $62: 180-190$.

da Rocha, Bruno T. and Solomos Solomou. 2015. “The effects of systemic banking crises in the inter-war period." Journal of International Money and Finance 54:35 -49 .

Dell'Ariccia, Giovanni, Enrica Detragiache, and Raghuram Rajan. 2008. “The real effect of banking crises.” Journal of Financial Intermediation 17 (1):89-112.

Dennis, Richard. 2009. "Consumption Habits in a New Keynesian Business Cycle Model.” Journal of Money, Credit and Banking 41 (5):1015-1030.

Elgin, Ceyhun and Oguz Oztunali. 2012. "Shadow Economies around the World: Model Based Estimates.” Working Papers 2012/05, Bogazici University, Department of Economics.

Epstein, Brendan and Alan Finkelstein Shapiro. 2017. "Employment and firm heterogeneity, capital allocation, and countercyclical labor market policies.” Journal of Development Economics 127 (C):25-41.

Fernández, Andrés and Felipe Meza. 2015. "Informal employment and business cycles in emerging economies: The case of Mexico.” Review of Economic Dynamics $18(2): 381-405$.

Fiess, Norbert M., Marco Fugazza, and William Maloney. 2010. "Informal selfemployment and macroeconomic fluctuations." Journal of Development Economics 91 (2):211-226. 
Furceri, Davide and Annabelle Mourougane. 2012. "The effect of financial crises on potential output: New empirical evidence from OECD countries." Journal of Macroeconomics 34 (3):822 - 832.

Furceri, Davide and Aleksandra Zdzienicka. 2012. "Banking Crises and Short and Medium Term Output Losses in Emerging and Developing Countries: The Role of Structural and Policy Variables.” World Development 40 (12):2369 - 2378.

Garcia-Cicco, Javier, Roberto Pancrazi, and Martin Uribe. 2010. "Real Business Cycles in Emerging Countries?” American Economic Review 100 (5):2510-2531.

Gertler, Mark and Peter Karadi. 2011. "A model of unconventional monetary policy.” Journal of Monetary Economics 58 (1):17-34.

Ha, Eunyoung and Myung-koo Kang. 2015. "Government Policy Responses to Financial Crises: Identifying Patterns and Policy Origins in Developing Countries." World Development 68:264 - 281.

Hobijn, Bart and Aysegül Sahin. 2009. "Job-finding and separation rates in the OECD.” Economics Letters 104 (3):107-111.

Horvath, Jaroslav. 2017. "Business Cycles, Informal Economy, and Interest Rates in Emerging Countries.” Journal of Macroeconomics .

Koreshkova, Tatyana A. 2006. "A quantitative analysis of inflation as a tax on the underground economy." Journal of Monetary Economics 53 (4):773-796.

Kroszner, Randall S., Luc Laeven, and Daniela Klingebiel. 2007. "Banking crises, financial dependence, and growth." Journal of Financial Economics 84 (1):187228.

La Porta, Rafael and Andrei Shleifer. 2008. “The Unofficial Economy and Economic Development.” Brookings Papers on Economic Activity 39 (2 (Fall)):275-363.

Laeven, Luc and Fabian Valencia. 2008. “Systemic Banking Crises: A New Database.” IMF Working Papers 08/224, International Monetary Fund.

2010. "Resolution of Banking Crises: The Good, the Bad, and the Ugly." IMF Working Papers 10/146, International Monetary Fund. 
Loayza, Norman V. and Jamele Rigolini. 2011. "Informal Employment: Safety Net or Growth Engine?” World Development 39 (9):1503-1515.

Medina, Leandro and Friedrich Schneider. 2018. "Shadow economies Around the World: What Did We Learn Over the Last 20 Years?” Working Paper 18/17, IMF.

Meghir, Costas, Renata Narita, and Jean-Marc Robin. 2015. "Wages and Informality in Developing Countries.” American Economic Review 105 (4):1509-1546.

Merz, Monika. 1995. "Search in the labor market and the real business cycle.” Journal of Monetary Economics 36 (2):269-300.

Ozkan, F. Gulcin and Filiz D Unsal. 2012. “Global Financial Crisis, Financial Contagion, and Emerging Markets.” IMF Working Papers 12/293, International Monetary Fund.

Pratap, Sangeeta and Erwan Quintin. 2006. “The Informal Sector in Developing Countries: Output, Assets and Employment.” Working Papers RP2006/130, World Institute for Development Economic Research (UNU-WIDER).

Rajan, Raghuram G and Luigi Zingales. 1998. “Financial Dependence and Growth.” American Economic Review 88 (3):559-86.

Reinhart, Carmen and Kenneth Rogoff. 2009. This Time Is Different. Eight Centuries of Financial Folly. Princeton University Press.

Restrepo-Echavarria, Paulina. 2014. "Macroeconomic volatility: The role of the informal economy.” European Economic Review 70 (C):454-469.

Romer, Christina D. and David H. Romer. 1989. “Does Monetary Policy Matter? A New Test in the Spirit of Friedman and Schwartz." In NBER Macroeconomics Annual 1989, Volume 4, NBER Chapters. National Bureau of Economic Research, Inc, 121-184.

Rotemberg, Julio J. 1982. “Monopolistic Price Adjustment and Aggregate Output.” Review of Economic Studies 49 (4):517-31.

Schmitt-Grohe, Stephanie and Martin Uribe. 2004. "Optimal fiscal and monetary policy under sticky prices.” Journal of Economic Theory 114 (2):198-230. 
Schneider, Friedrich, Andreas Buehn, and Claudio E. Montenegro. 2010. "Shadow economies all over the world : new estimates for 162 countries from 1999 to 2007." Policy Research Working Paper Series 5356, The World Bank.

Schneider, Friedrich G. and Andreas Buehn. 2007. "Shadow economies and corruption all over the world: revised estimates for 120 countries." Economics - The Open-Access, Open-Assessment E-Journal 1 (9 (Versio):1-53.

Toracchi, Federico. 2017. “How Do Credit Supply Conditions Affect the Labor Market? Estimating a New-Keynesian DSGE Model with Labor and Credit Market Frictions.” Tech. Rep. 817, University of Oxford.

Ulyssea, Gabriel. 2010. "Regulation of entry, labor market institutions and the informal sector.” Journal of Development Economics 91 (1):87 - 99.

Zenou, Yves. 2008. "Job search and mobility in developing countries. Theory and policy implications.” Journal of Development Economics 86 (2):336-355.

Zhang, Yahong. 2011. "Financial Frictions, Financial Shocks and Labour Market Frictions in Canada.” Discussion paper no. 2011-10, Bank of Canada. 


\section{Notes}

${ }^{1}$ See also Fiess, Fugazza, and Maloney (2010).

${ }^{2}$ Some national statistical offices include in official statistics some estimate of informal employment. As documented in Fernández and Meza (2015) for the case of Mexico, this is not sufficient to alter the correlations between formal and informal employment.

${ }^{3}$ The ILO dataset is also the basis of data on the participation rate included in the World Bank WDI.

${ }^{4}$ See Schneider, Buehn, and Montenegro (2010)

${ }^{5}$ See in particular the technical appendix to the paper available at: https://sites .google.com/site/andresferna

${ }^{6}$ In the Appendix we report the Im-Pesaran-Shin panel unit root test for the dependent variables. The number of lags of both the dependent variable and the crisis dummy have been chosen to maximize the informativeness of the model given the relatively short sample period.

${ }^{7}$ Robust standard errors apply Windmeijer's finite sample correction. The results are robust to changes in the lag distribution.

${ }^{8}$ Additional results available upon request.

${ }^{9}$ See the Appendix for a full derivation of the model.

${ }^{10}$ By contrast, Fiess, Fugazza, and Maloney (2010) identify the informal sector with self-employed workers.

${ }^{11}$ We assume that bankers share consumption risk with remaining individuals in the household. In addition, they inelastically supply a unit of labor in each period.

${ }^{12}$ Other contributions assume a non-segmented, fully competitive labor market in the informal economy (Amaral and Quintin (2006) and Pratap and Quintin (2006)).

${ }^{13}$ Following Gertler and Karadi (2011) $\Pi_{t}^{o}$ incorporates profits from both official sector retail firms and banks, as well as transfers from individuals exiting the banking profession and to new bankers, as discussed below.

${ }^{14} \mathrm{We}$ assume that $f_{p v}^{E A} V_{t}$ is purchased in the goods market, as such it enters the official sector aggregate resource constraint below.

${ }^{15}$ This assumption is typically made to prevent bankers from accumulating net worth up to the point where they would no longer need deposits to supply loans. 
Figure 1: Informal employment around episodes of banking crises
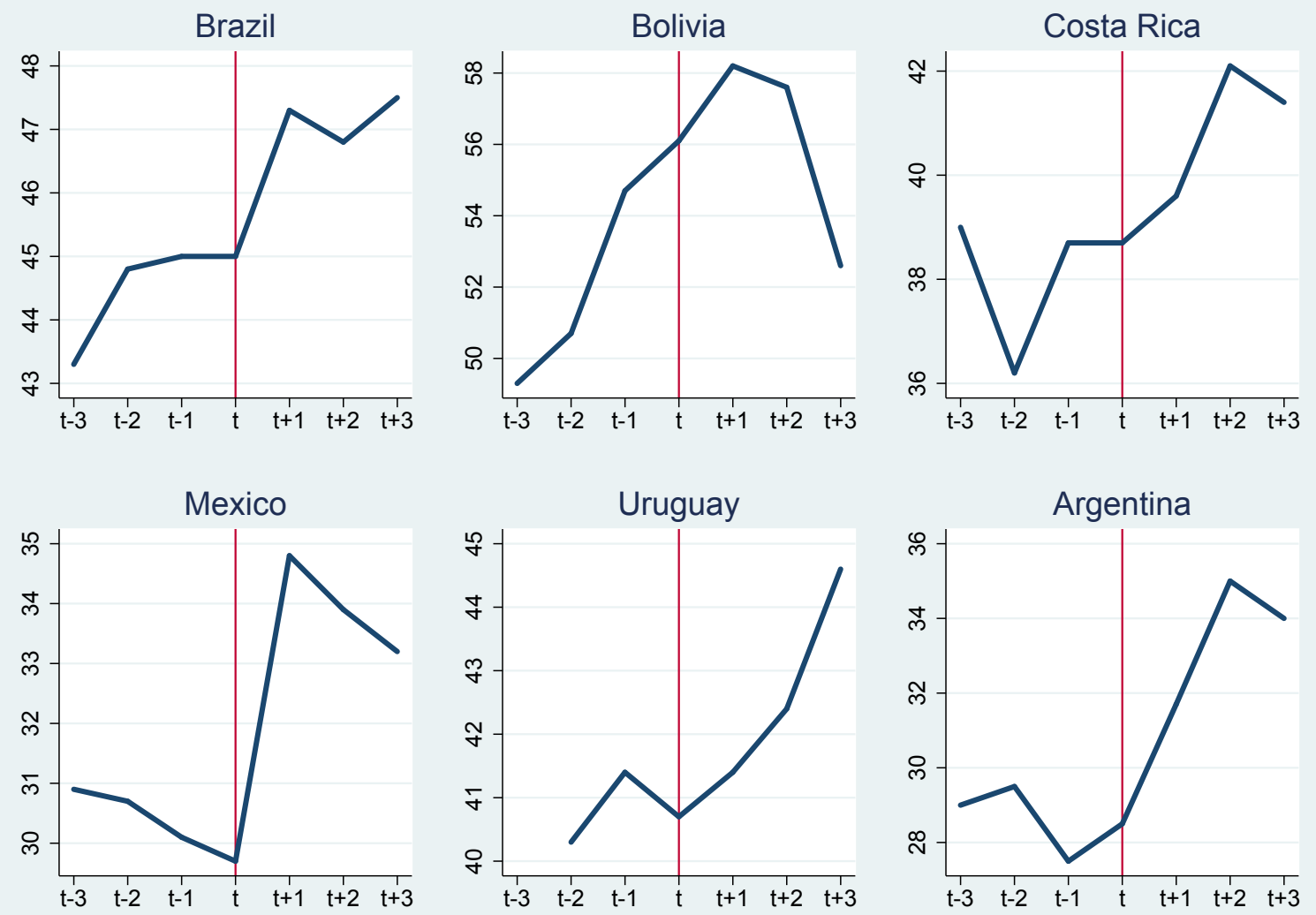

Note: Figures report the share of persons employed in informal activity in total non agricultural employment. $t$ refers to the date of banking crisis and is as follows: Brazil, Mexico, Costa Rica and Bolivia 1994, Argentina 2001, Uruguay 2002. 
Figure 2: Response to banking crises
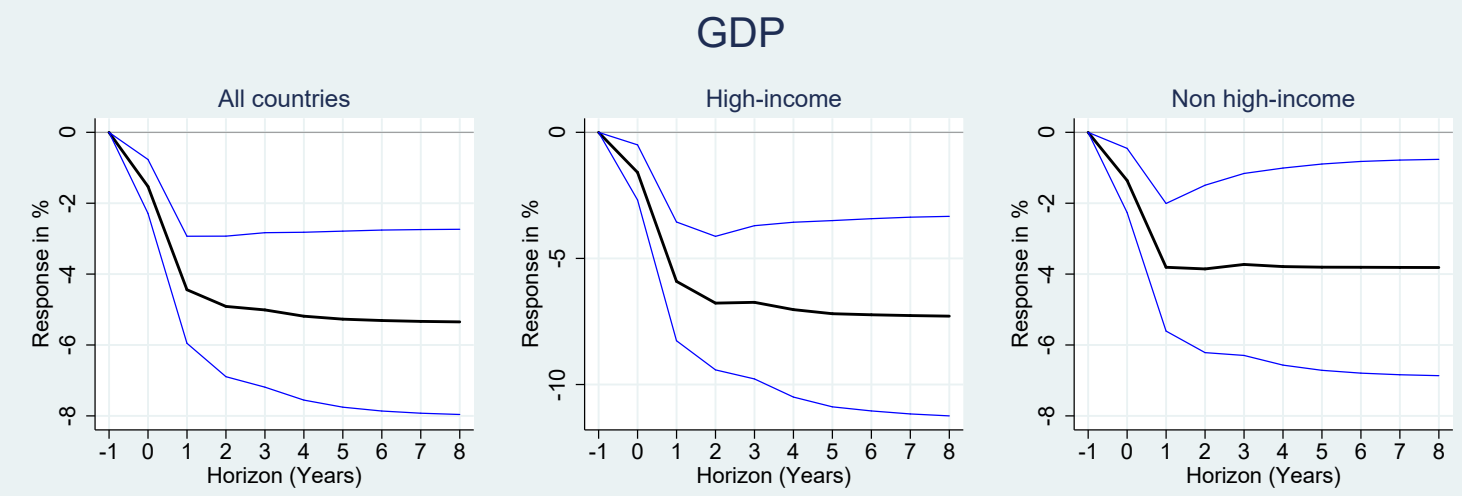

\section{Investment}
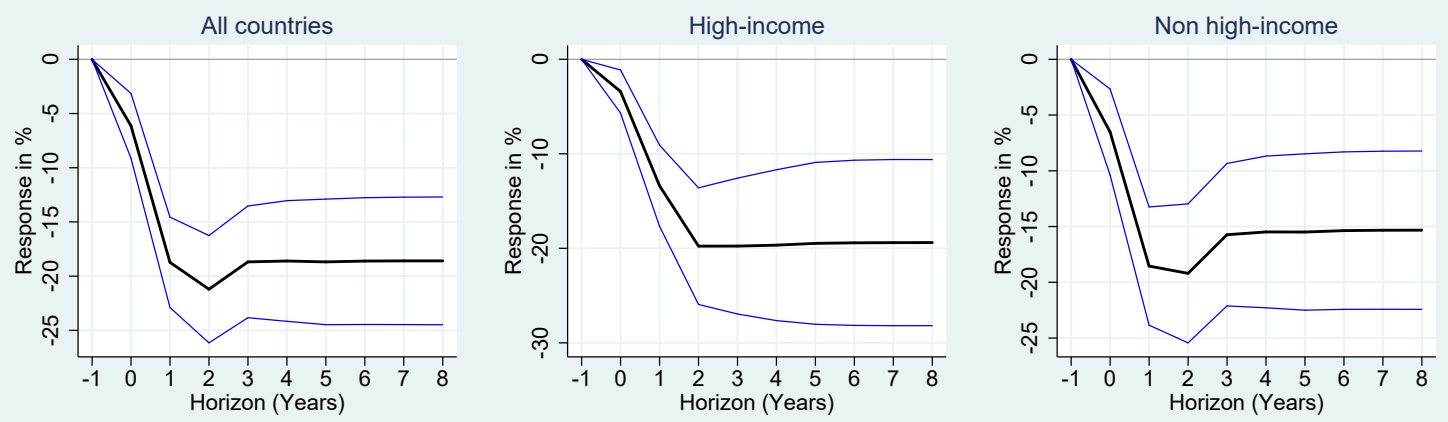

Note: the black line denotes estimated effect; light blue lines denote 90 percent confidence bands. $\mathrm{X}$-axis units are years; $\mathrm{t}=0$ denotes the year of the financial crisis. 
Figure 3: Response of participation rate to banking crises

\section{Participation rate}

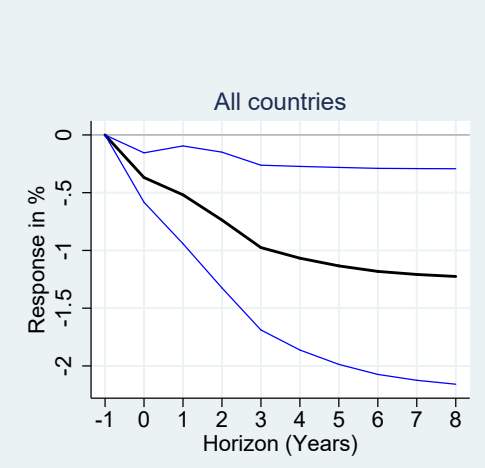

\section{KILM dataset}
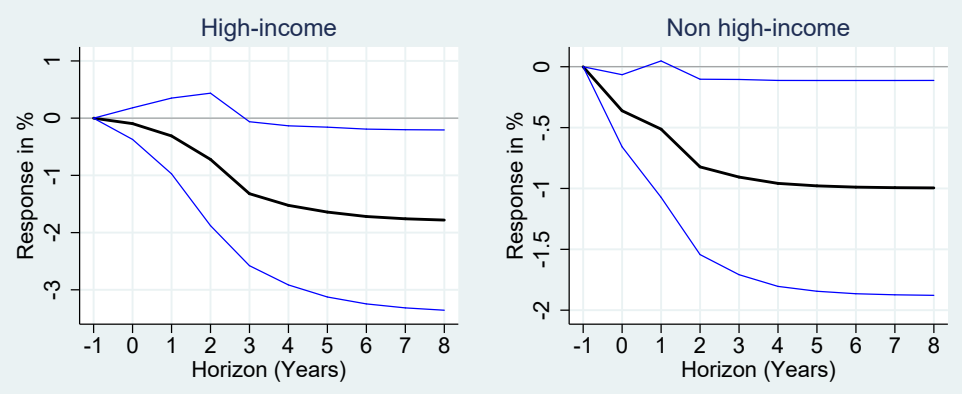

OECD dataset
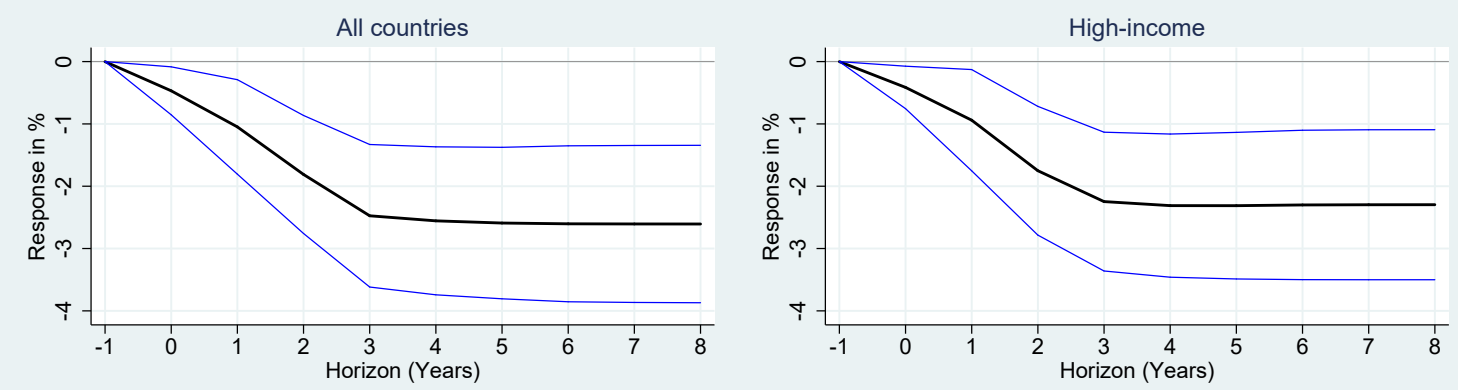

Note: the black line denotes estimated effect; light blue lines denote 90 percent confidence bands. $\mathrm{X}$-axis units are years; $\mathrm{t}=0$ denotes the year of the financial crisis. 
Figure 4: Response of unemployment rate to banking crises

\section{Unemployment rate}

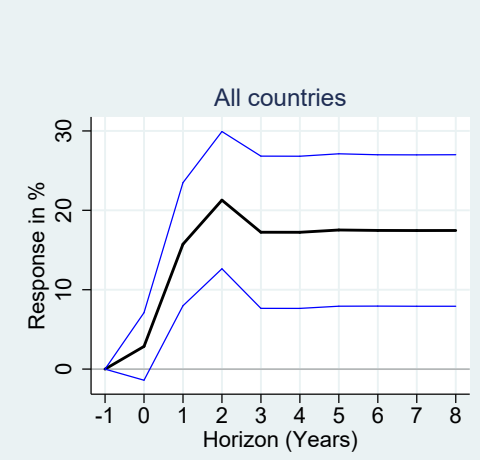

KILM dataset
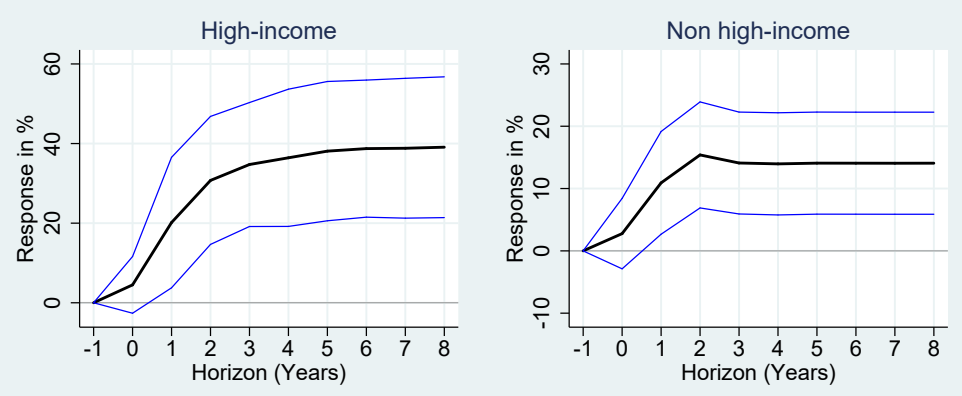

OECD dataset
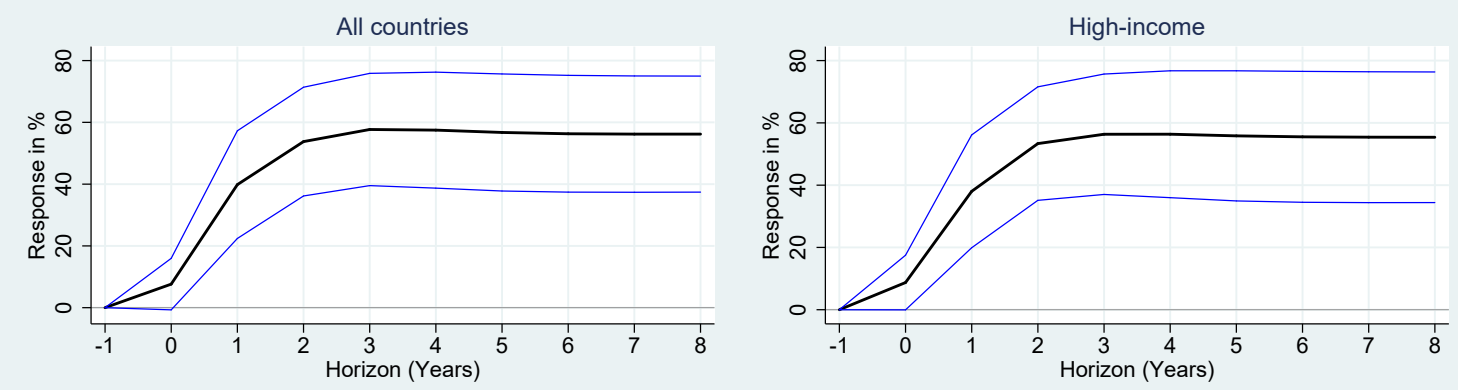

Note: the black line denotes estimated effect; light blue lines denote 90 percent confidence bands. $\mathrm{X}$-axis units are years; $\mathrm{t}=0$ denotes the year of the financial crisis. 
Figure 5: Response of employment rate to banking crises

\section{Employment rate}
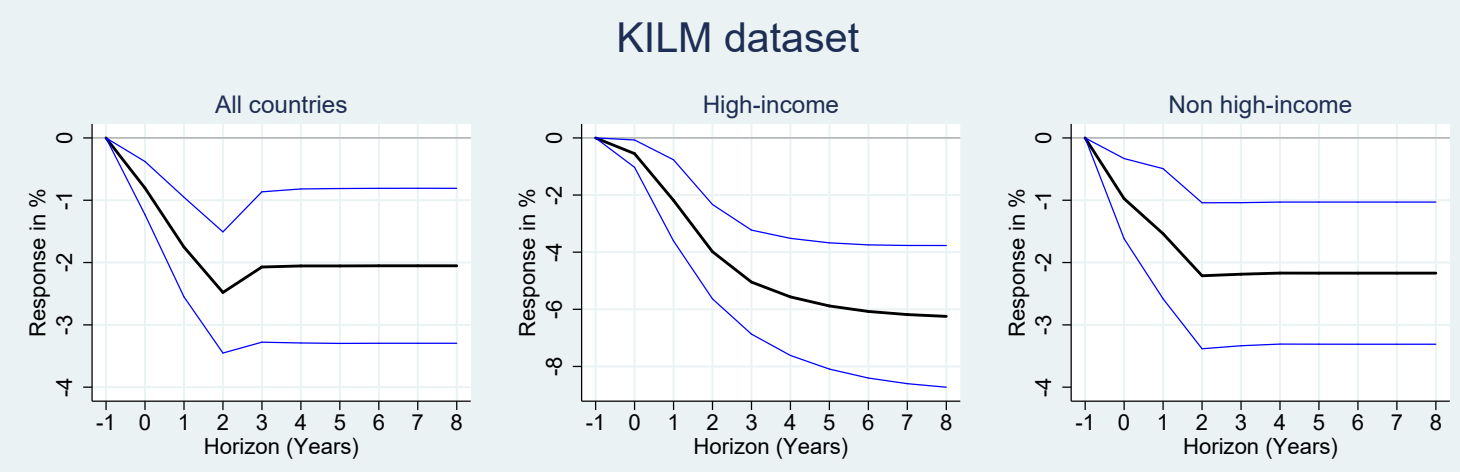

OECD dataset
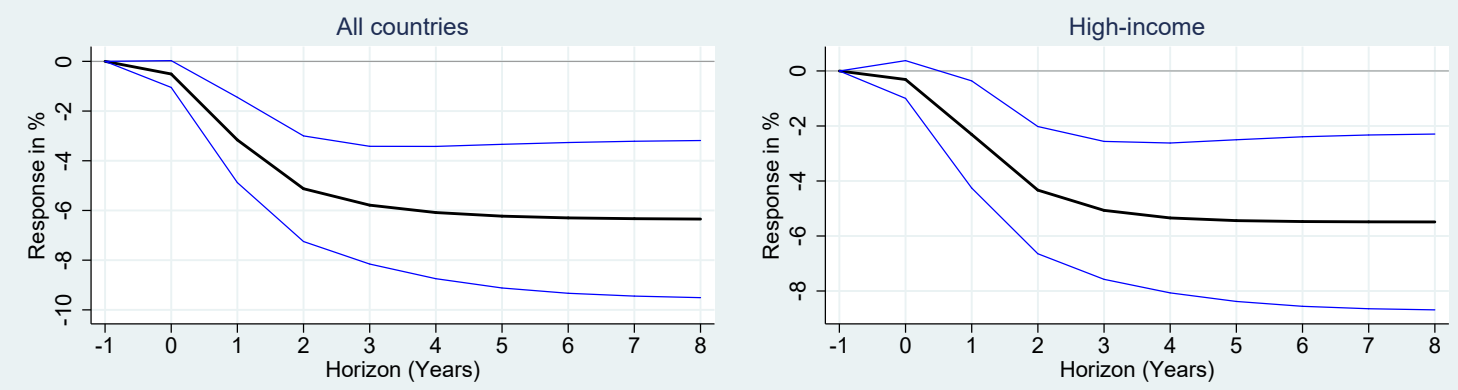

Note: the black line denotes estimated effect; light blue lines denote 90 percent confidence bands. $\mathrm{X}$-axis units are years; $\mathrm{t}=0$ denotes the year of the financial crisis. 
Figure 6: Response of informal economy to banking crises

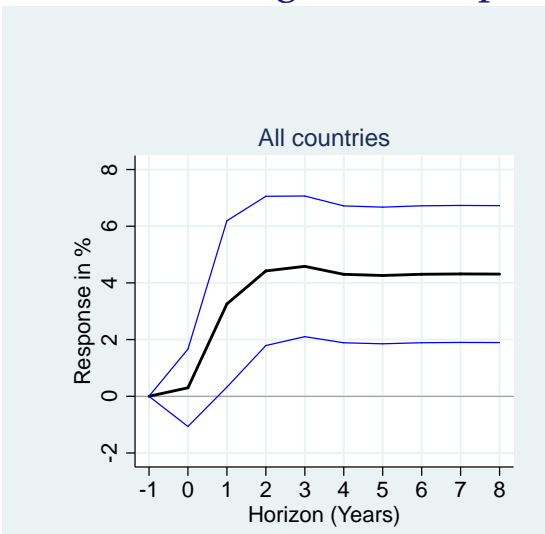

\section{Self employment ratio}
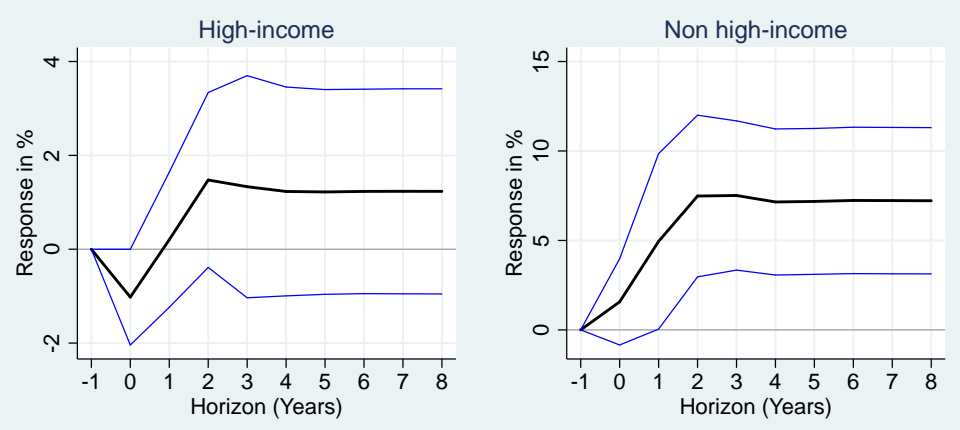

Shadow economy share
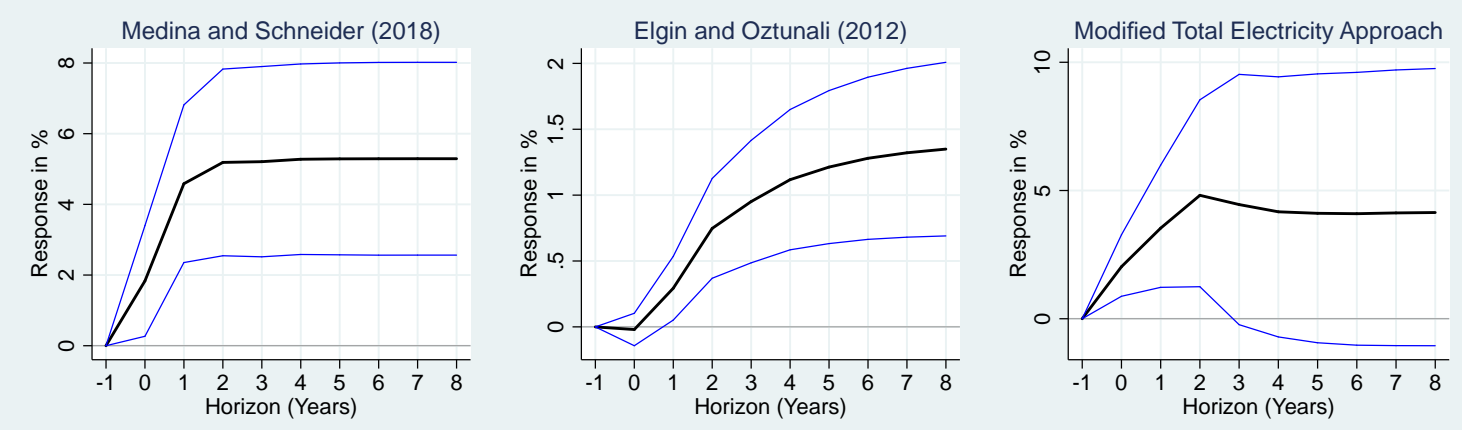

Note: the black line denotes estimated effect; light blue lines denote 90 percent confidence bands. $\mathrm{X}$-axis units are years; $\mathrm{t}=0$ denotes the year of the financial crisis. The upper panels represent IRFs of the self employment rate, the lower panels represent IRFs of different measures of informal economic activity 
Figure 7: Impulse responses to permanent shock to net worth. Part 1/2
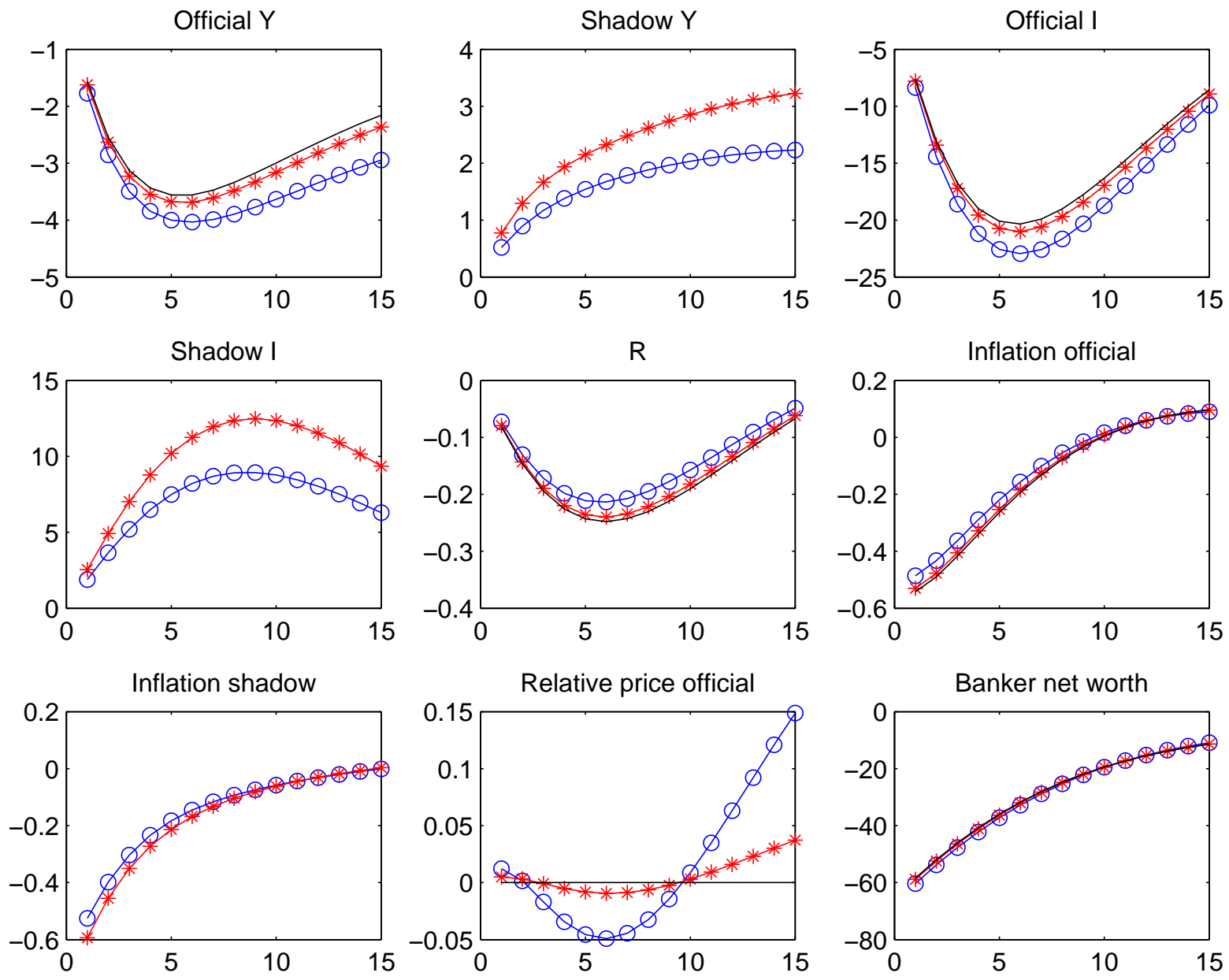

Note: the black line denotes IRF of the standard one sector model without the informal economy; the starred red line denotes the two sector model when the share of the informal economy is $8 \%$; the dotted blue line denotes the two sector model when the share of the informal economy is $40 \%$. Figures are percentage deviations from the steady state. 
Figure 8: Impulse responses to permanent shock to net worth. Part 2/2
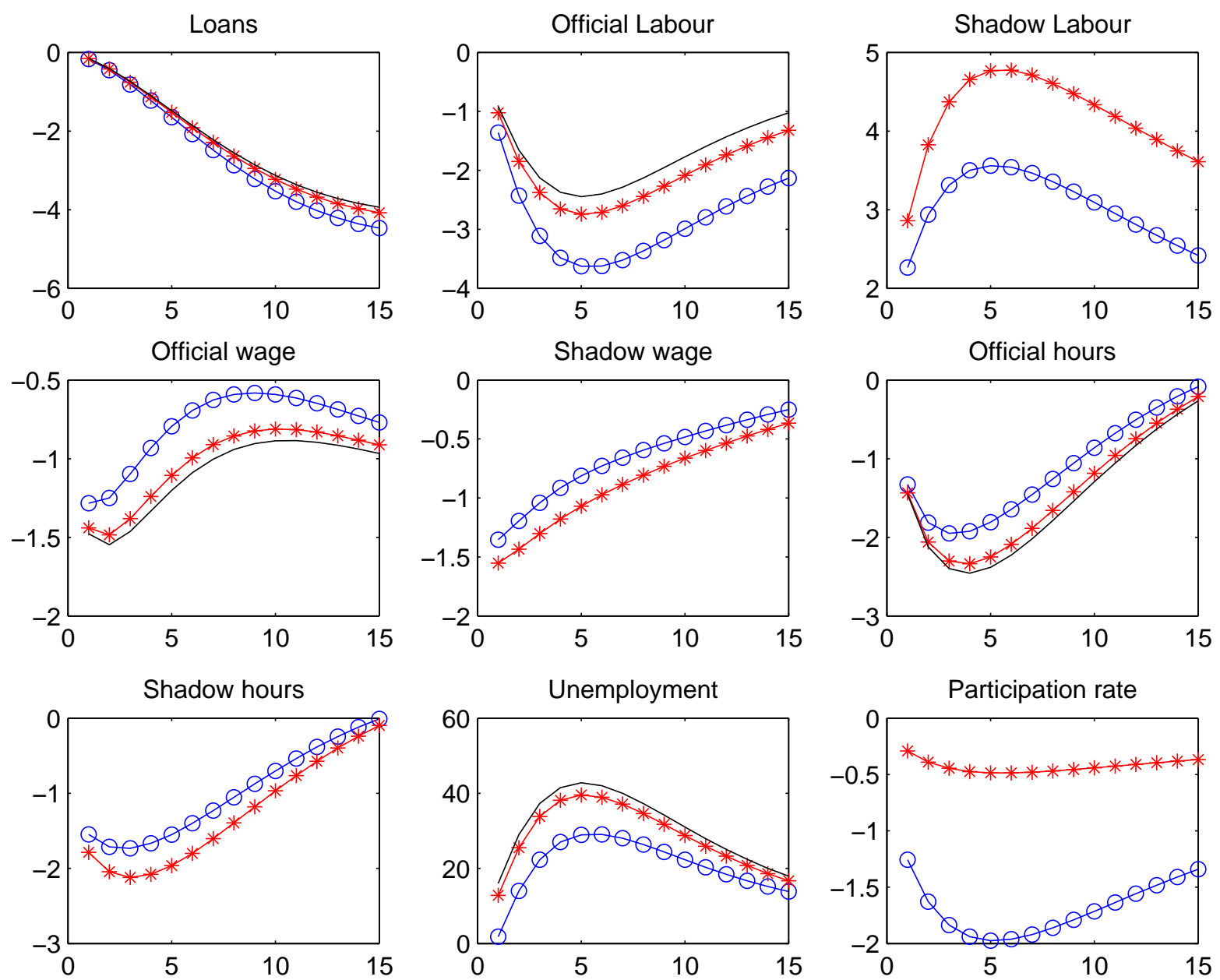

Note: the black line denotes IRF of the standard one sector model without the informal economy; the starred red line denotes the two sector model when the share of the informal economy is $8 \%$; the dotted blue line denotes the two sector model when the share of the informal economy is $40 \%$. Figures are percentage deviations from the steady state. 
Figure 9: The role of price stickiness and investment costs.
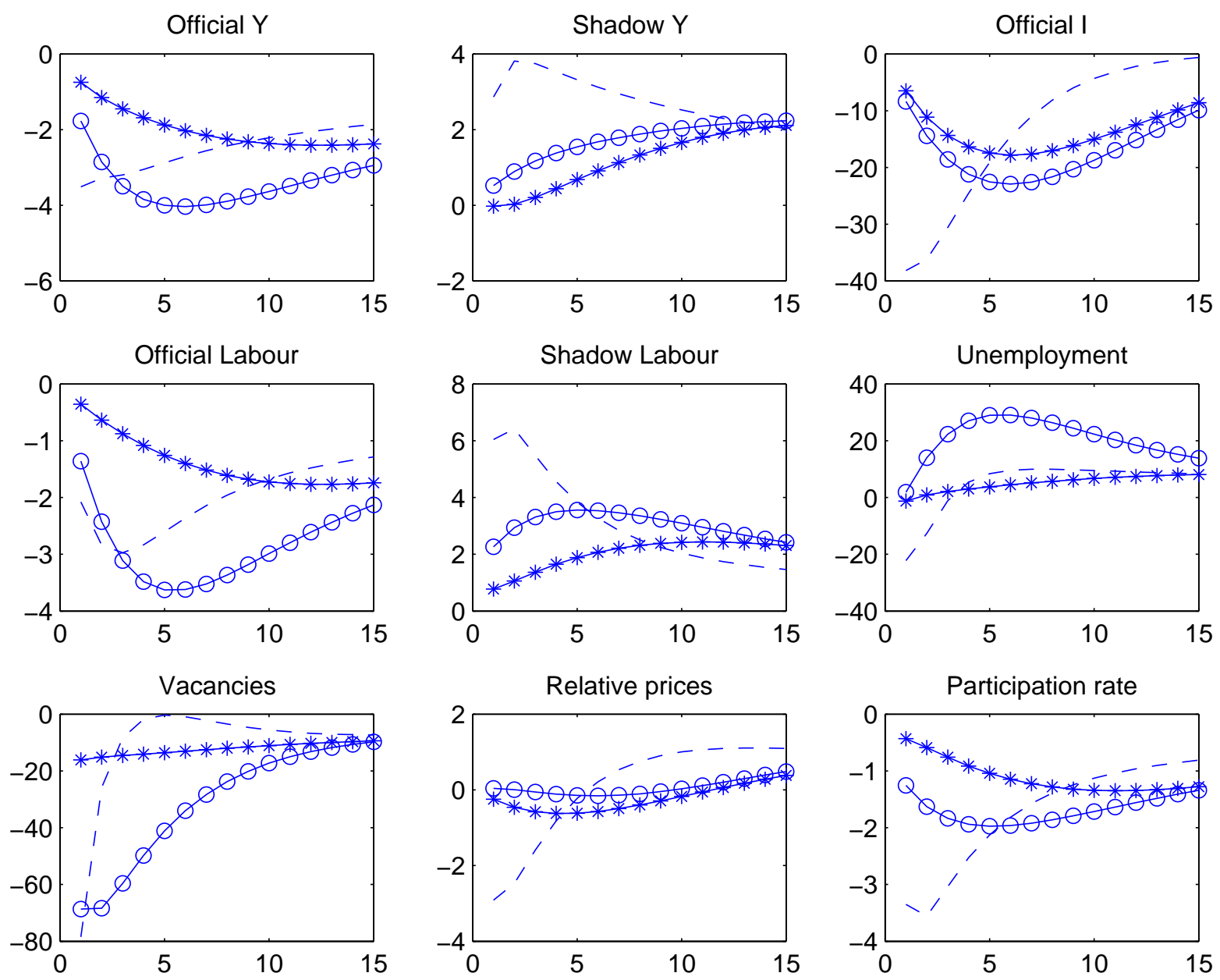

Note: the dotted blue line denotes IRF of the baseline model with a $40 \%$ share of informal economy; the starred blue line denotes the IRF of the same model where we remove price stickiness; the dashed blue line denotes the IRF of the model without price stickiness and investment adjustment costs. 
Figure 10: The effect of monetary policy.

Official $Y$
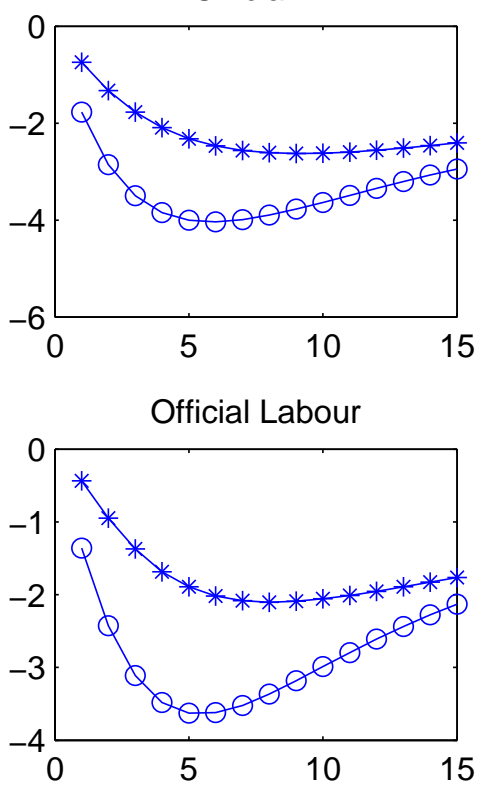

Vacancies

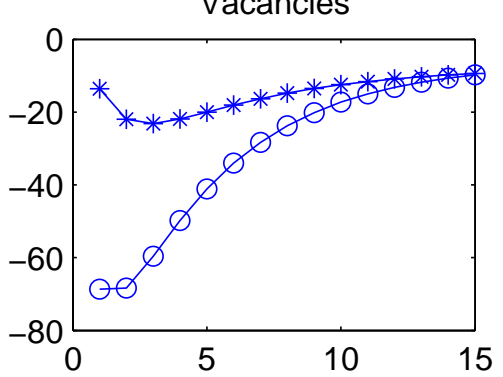

Shadow $Y$

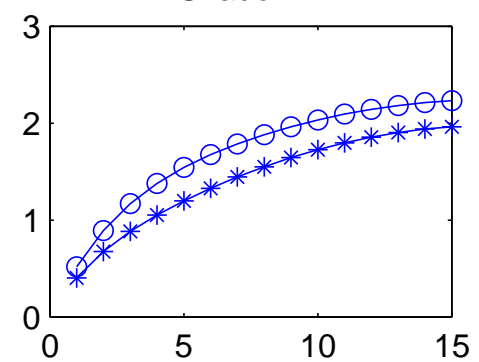

Shadow Labour

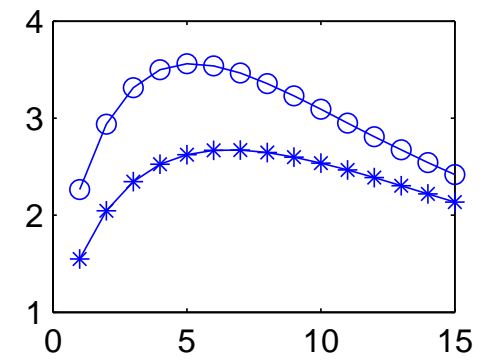

Relative prices

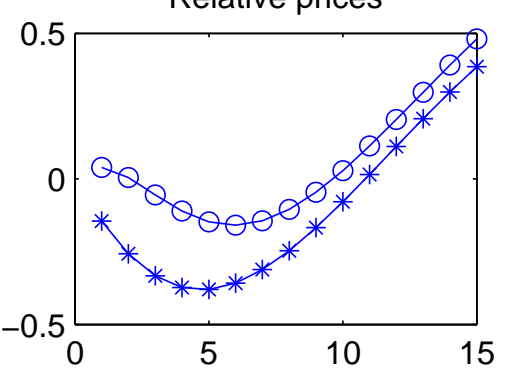

Official I

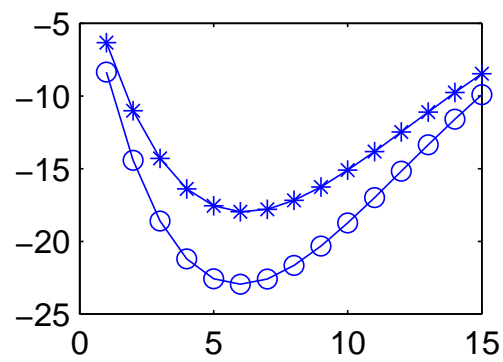

Unemployment

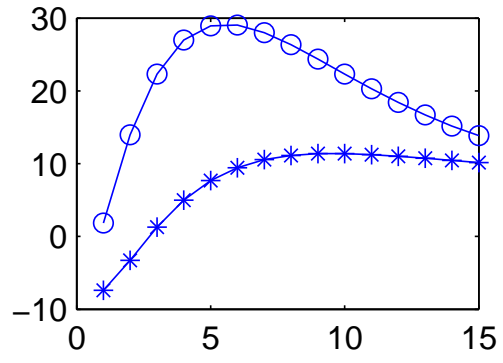

Participation rate

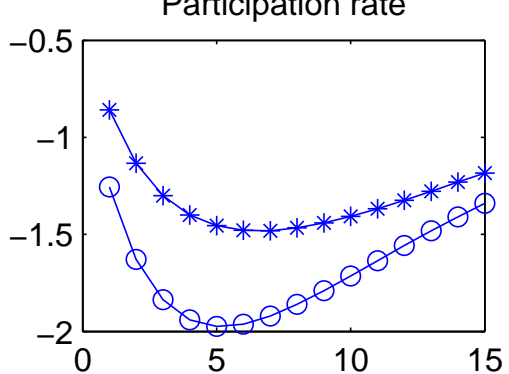

Note: the dotted blue line denotes IRF of the baseline model with a $40 \%$ share of informal economy; the starred blue line denotes the IRF of the same model where the monetary policy displays a stronger response to the shock. 
Figure 11: Impulse responses to permanent shock to net worth. Model with search frictions.
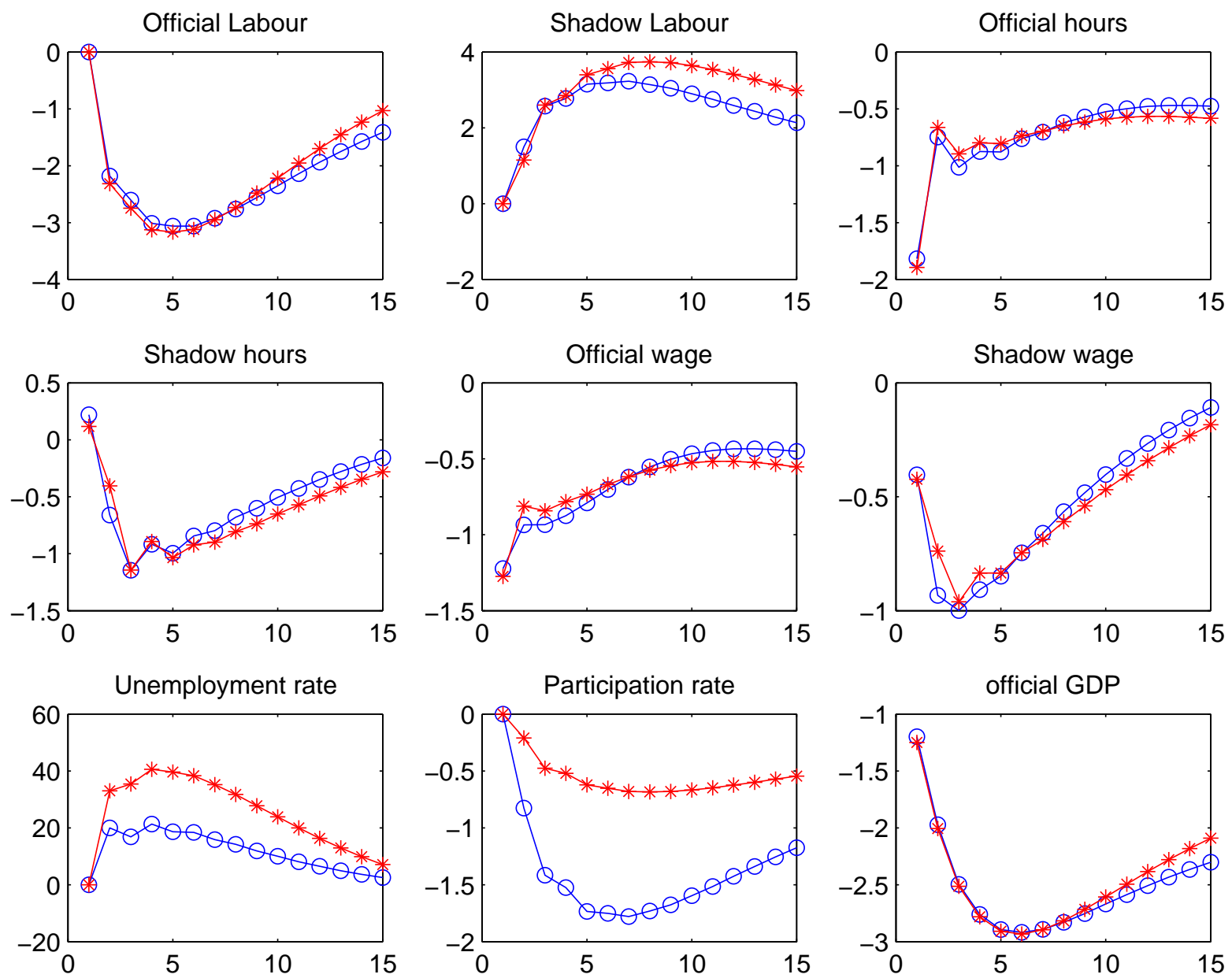

Note: the starred red line denotes the two sector model when the share of the informal economy is $8 \%$; the dotted blue line denotes the two sector model when the share of the informal economy is $40 \%$. Figures are percentage deviations from the steady state. 


\section{Technical Appendix}

\section{A.1 Model details}

\section{A.1.1 Households}

Households preferences are defined by:

$$
U_{t}=E_{t} \sum_{k=o}^{\infty} \beta^{k}\left\{\ln \left(c_{t+k}^{i}-b c_{t+k-1}\right)-\left(\frac{\chi\left(h_{t+k}^{i}\right)^{1+\phi} l_{t+k}^{i, o}}{1+\phi}\right)\right\}
$$

where $c^{i}$ is individual consumption, $b$ defines consumption habits and $l^{i}$ and $h_{t}^{i}$ respectively are the number of employed individuals and their labor effort in the official and informal economy sectors. ${ }^{16}$

Household preferences over the goods produced in sector $j$ of the economy are defined as follows:

$$
c_{t}^{j}=\left(\int_{0}^{1} c_{t}^{j}\left(z^{j}\right)^{\frac{\sigma^{j}-1}{\sigma j}} d z^{j}\right)^{\frac{\sigma^{j}}{\sigma j-1}}
$$

and the associated retail price index is:

$$
P_{t}^{R j}=\left(\int_{0}^{1}\left(P_{t}^{R j}(z)\right)^{1-\sigma^{j}} d z\right)^{\frac{1}{1-\sigma^{j}}}
$$

It follows that demand functions for individual goods within each consumption bundle are:

$$
c_{t}\left(z^{j}\right)=\left(\frac{P_{t}^{R j}\left(z^{j}\right)}{P_{t}^{R j}}\right)^{-\sigma^{j}} c_{t}^{j}
$$

Following Fernández and Meza (2015) and Restrepo-Echavarria (2014) the total consumption bundle is ${ }^{17}$

$$
c_{t}=\left[\left(1-\alpha_{c}\right)^{\frac{1}{\varepsilon}}\left(c_{t}^{o}\right)^{\frac{\varepsilon-1}{\varepsilon}}+\left(\alpha_{c}\right)^{\frac{1}{\varepsilon}}\left(c_{t}^{s}\right)^{\frac{\epsilon-1}{\varepsilon}}\right]^{\frac{\varepsilon}{\varepsilon-1}}
$$

and

$$
P_{t}=\left[\left(1-\alpha_{c}\right)\left(P_{t}^{R, o}\right)^{1-\varepsilon}+\alpha_{c}\left(P_{t}^{R, s}\right)^{1-\varepsilon}\right]^{\frac{1}{1-\varepsilon}}
$$

defines the consumption price index. Demand functions for the sectoral consumption bundles are: 


$$
\begin{gathered}
c_{t}^{o}=\left(1-\alpha_{c}\right)\left(\frac{P_{t}^{R, o}}{P_{t}}\right)^{-\varepsilon} c_{t} \\
c_{t}^{s}=\alpha_{c}\left(\frac{P_{t}^{R, s}}{P_{t}}\right)^{-\varepsilon} c_{t}
\end{gathered}
$$

The representative household flow budget constraint is:

$$
\begin{aligned}
& c_{t}+\frac{P_{t}^{R, o}}{P_{t}} D_{t}+\frac{P_{t}^{R, s}}{P_{t}} I_{t}^{s}= \\
= & \frac{P_{t}^{R, o}}{P_{t}} w_{t}^{o} h^{o} l_{t}^{o}+b^{u} u_{t}+\frac{P_{t}^{R, o}}{P_{t}} R_{t-1}^{D} D_{t-1} \\
& +\frac{P_{t}^{R, s}}{P_{t}} w_{t}^{s} h^{s} l_{t}^{s}+\frac{P_{t}^{R, s}}{P_{t}}\left(r_{t}^{k . s}-\delta\right) k_{t-1}^{s}+\frac{P_{t}^{R, o}}{P_{t}} \Pi_{t}^{o}+\frac{P_{t}^{R, s}}{P_{t}} \Pi_{t}^{s}
\end{aligned}
$$

where $D$ are bank deposits, which yield the rate of return $R_{t}^{D}, k^{s}$ and $I_{t}^{s}$ are the capital stock and the amount of investment in the informal sector, $r^{k, s}$ is the return from capital investment in the informal economy and $\delta$ is the capital depreciation rate. $\Pi^{o}$ and $\Pi^{s}$ define sectoral profits. ${ }^{18}$ Note that households choose investment in the informal sector, whereas official investment is chosen by official firms.

The household marginal utility of consumption is:

$$
\lambda_{t}=\frac{1}{\left(c_{t}-b c_{t-1}\right)}
$$

The intertemporal Euler equations for deposits, $D_{t}$ and for informal sector capital are:

$$
\begin{gathered}
\lambda_{t}=\beta E_{t} \frac{\pi_{t+1}^{R, o} \lambda_{t+1}}{\pi_{t+1}} R_{t}^{D} \\
1=\beta E_{t} \frac{\lambda_{t+1}}{\lambda_{t}} \frac{\left[q_{t+1}^{s}(1-\delta)+\frac{P_{t+1}^{R, s}}{P_{t+1}} r_{t+1}^{k, s}\right]}{q_{t}^{s}}
\end{gathered}
$$

Accumulation of $k_{t}^{s}$ is driven by:

$$
k_{t}^{s}=(1-\delta) k_{t-1}^{s}+\left[1-S\left(\frac{I_{t}^{s}}{I_{t-1}^{s}}\right)\right] I_{t}^{s}
$$

where $q_{t}^{s}$ is the informal sector relative price of capital, defined in terms of the consumption bundle (A.3), $\pi_{t}, \pi_{t}^{R, o}$ respectively define inflation rates for $P_{t}, P_{t}^{R, o}$ and $S\left(\frac{I_{t}^{s}}{I_{t-1}^{s}}\right)=\frac{\gamma_{I}}{2}\left(\frac{I_{t}^{s}}{I_{t-1}^{s}}-1\right)^{2}$ investment adjustment costs.

The first order condition for investment decisions in the informal sector is: 


$$
\begin{aligned}
\frac{P_{t}^{R, s}}{P_{t}}= & q_{t}^{s}\left\{1-\gamma_{I}\left(\frac{I_{t}^{s}}{I_{t-1}^{s}}-1\right) \frac{I_{t}^{s}}{I_{t-1}^{s}}-\frac{\gamma_{I}}{2}\left(\frac{I_{t}^{s}}{I_{t-1}^{s}}-1\right)^{2}\right\} \\
& +\beta \frac{\lambda_{t+1}}{\lambda_{t}} q_{t+1}^{s} \gamma_{I}\left(\frac{I_{t+1}^{s}}{I_{t}^{s}}-1\right)\left(\frac{I_{t+1}^{s}}{I_{t}^{s}}\right)^{2}
\end{aligned}
$$

\section{A.1.2 Labor market}

The labor market is perfectly competitive in the unofficial sector, but is characterized by matching frictions in the official sector. Following Christiano, Trabandt, and Walentin (2011) and Zhang (2011), to facilitate model tractability we assume that employment agencies post vacancies in the official labor market at the official output cost $f_{p v}^{E A}$ and bargain with workers both the official sector product wage rate $w_{t}^{o}$ and the number of hours worked $h^{o}$. Subsequently they combine individual labor supplies into a labor input which is then transferred to official sector wholesale firms at the competitive price $P_{t}^{E A}$, defined in terms of official sector goods.

\section{A.1.2.1 Employment agencies}

In the formal sector new matches per unit of time are determined by a standard matching technology:

$$
M_{t}=m\left(u_{t}\right)^{\varkappa}\left(V_{t}\right)^{1-\varkappa}
$$

where $V_{t}$ and $u_{t}$ respectively define the number of vacancies in the official sector and unemployment, and $m$ is a parameter that defines the efficiency of the matching technology. The probability that a vacancy $z_{t}^{V}$ be filled therefore is:

$$
z_{t}^{V}=\frac{M_{t}}{V_{t}}=m\left(\frac{u_{t}}{V_{t}}\right)^{\varkappa} .
$$

Similarly, the probability that an unemployed individual gets a job in the official sector, $z_{t}^{u n}$, is:

$$
z_{t}^{u n}=\frac{M_{t}}{u_{t}}=m\left(\frac{V_{t}}{u_{t}}\right)^{1-\varkappa}
$$

Real profits of the representative employment agency are:

$$
\Pi^{E A}=\left(P_{t}^{E A}-w_{t}^{o}\right) l_{t}^{o} h_{t}^{o}-f_{p v}^{E A} V_{t}
$$


Official employment follows the law of motion:

$$
l_{t}^{o}(s)=\rho^{s} l_{t-1}^{o}(s)+z_{t}^{V} V_{t}(s)
$$

where $\rho^{s}\left(0<\rho^{s}<1\right)$ defines the exogenous probability that a match survives up to next period.

The employment agency maximizes:

$$
E_{t} \sum_{k=o}^{\infty} \beta \frac{\pi_{t+1}^{R, o}}{\pi_{t+1}} \frac{\lambda_{t+1}}{\lambda_{t}}\left[\left(P_{t}^{E A}-w_{t}^{o}\right) l_{t}^{o} h_{t}^{o}-f_{p v}^{E A} V_{t}\right]
$$

subject to (A.10) by optimally choosing the number of workers and the number of vacancies. The first order conditions are:

$$
\frac{P_{t}^{R, o}}{P_{t}} \lambda_{t}\left(P_{t}^{E A}-w_{t}^{o}\right) h_{t}^{o}-\frac{P_{t}^{R, o}}{P_{t}} \lambda_{t} v_{t}^{E A}+\beta \frac{P_{t+1}^{R, o}}{P_{t+1}} \lambda_{t+1} v_{t+1}^{E A} \rho^{S}=0
$$

and:

$$
f_{p v}^{E A}=v_{t}^{E A} z_{t}^{V}
$$

Combining the two, we obtain the the following hiring condition:

$$
\frac{f_{p v}^{E A}}{z_{t}^{V}}=\left(P_{t}^{E A}-w_{t}^{o}\right) h_{t}^{o}+\beta \frac{\pi_{t+1}^{R, o} \lambda_{t+1}}{\pi_{t+1} \lambda_{t}} \frac{f_{p v}^{E A}}{z_{t+1}^{V}} \rho^{S}
$$

where $\frac{f_{p v}^{E A}}{z_{t}^{V}}$ defines the marginal cost of hiring a worker ${ }^{19}$ and the r.h.s. of (A.11) is the marginal benefit, including both the price margin $\left(P_{t}^{E A}-w_{t}^{o}\right)$, and the discounted savings on posting a future vacancy, which are proportional to the match survival rate $\rho^{s}$.

\section{A.1.2.2 Nash bargaining over wages and hours}

The nominal wage and the number of hours are negotiated by workers and employment agencies within a Nash bargaining framework. We assume simultaneous bargaining over $W$ and $h$.

The Bellman equation that describes the value of a new hire for the employment agency is: 


$$
v_{t}^{E A}=\left(P_{t}^{E A}-w_{t}^{o}\right) h_{t}^{o}+\beta \frac{\pi_{t+1}^{R, o} \lambda_{t+1}}{\pi_{t+1} \lambda_{t}} v_{t+1}^{E A} \rho^{S}
$$

where $v_{t}^{E A}$ is defined in official goods. The Bellman equations that describe the value for an individual of being employed and unemployed respectively are:

$$
\begin{gathered}
v_{t}^{l o}=\lambda_{t} \frac{P_{t}^{R, o}}{P_{t}} w_{t}^{o} h_{t}^{o}-\chi \frac{h_{t}^{o(1+\phi)}}{1+\phi}+\beta\left[\rho v_{t+1}^{l o}+(1-\rho) v_{t+1}^{u}\right] \\
v_{t}^{u}=\lambda_{t} \frac{P_{t}^{R, o}}{P_{t}} b^{u}+\beta\left[z_{t+1}^{u n} v_{t+1}^{l o}+\left(1-z_{t+1}^{u n}\right) v_{t+1}^{u}\right]
\end{gathered}
$$

where $b^{u}$ defines the value of being unemployed in period $t$. Bosch and EstebanPretel (2012) point out that this value may capture elements such as the value of leisure, unemployment benefits and home production, which they treat as distinct from informal employment. Note that the option value of being employed in the unofficial sector does not enter (A.12) and (A.13) because we impose the stock equilibrium condition:

$$
v_{t}^{u}=v_{t}^{s}
$$

where

$$
v_{t}^{s}=\lambda_{t} \frac{P_{t}^{R, s}}{P_{t}} w_{t}^{s} h_{t}^{s}-\chi_{t} \frac{h_{t}^{s(1+\phi)}}{1+\phi}+\beta v_{t+1}^{s}
$$

defines the value to the individual of being employed in the unofficial sector.

Wages and hours are set to maximize the product:

$$
\left(v_{t}^{E A}\right)^{1-\vartheta}\left(v_{t}^{l o}-v_{t}^{u}\right)^{\vartheta}
$$

where $\vartheta$ identifies the relative bargaining power of each party.

The foc with respect to wages and hours respectively are:

$$
\begin{aligned}
& (1-\theta)\left(v_{t}^{e a}\right)^{-\theta} \frac{\partial v_{t}^{e a}}{\partial w_{t}^{o}}\left(v_{t}^{l o}-v_{t}^{u}\right)^{\theta}=-\theta\left(v_{t}^{e a}\right)^{1-\theta}\left(v_{t}^{l o}-v_{t}^{u}\right)^{\theta-1} \frac{\partial\left(v_{t}^{l o}-v_{t}^{u}\right)}{\partial w_{t}^{o}}= \\
= & (1-\theta)\left(\chi \frac{h_{t}^{o(1+\phi)}}{\left(\frac{\lambda_{t} P_{t}^{R, o}}{P_{t}}\right)(1+\phi)}+b^{u}\right)+\theta\left\{P_{t}^{E A} h_{t}^{o}+\beta \frac{\lambda_{t+1} \pi_{t+1}^{R, o}}{\lambda_{t} \pi_{t+1}} z_{t+1}^{u n} v_{t+1}^{e a}\right\}
\end{aligned}
$$




$$
\begin{aligned}
(1-\theta)\left(v_{t}^{e a}\right)^{-\theta} \frac{\partial v_{t}^{e a}}{\partial h_{t}^{o}}\left(v_{t}^{l o}-v_{t}^{u}\right)^{\theta} & =-\theta\left(v_{t}^{e a}\right)^{1-\theta}\left(v_{t}^{l o}-v_{t}^{u}\right)^{\theta-1} \frac{\partial\left(v_{t}^{l o}-v_{t}^{u}\right)}{\partial w h_{t}^{o}}= \\
-\theta\left(v_{t}^{e a}\right) \frac{\partial\left(v_{t}^{l o}-v_{t}^{u}\right)}{\partial h_{t}^{o}} & =(1-\theta) \frac{\partial v_{t}^{e a}}{\partial h_{t}^{o}}\left(v_{t}^{l o}-v_{t}^{u}\right) \\
-\theta\left(v_{t}^{e a}\right) \lambda_{t}\left(\frac{P_{t}^{R, o}}{P_{t}} w_{t}^{o}-\chi h_{t}^{o(\phi)}\right) & =(1-\theta)\left(P_{t}^{E A}-w_{t}^{o}\right)\left(v_{t}^{l o}-v_{t}^{u}\right)
\end{aligned}
$$

Since, $\frac{\theta}{(1-\theta)}\left(v_{t}^{e a}\right) \frac{\lambda_{t} P_{t}^{R, o}}{P_{t}}=\left(v_{t}^{l o}-v_{t}^{u}\right)$ we get:

$$
\chi h_{t}^{o(\phi)}=P_{t}^{E A}
$$

also note that Nash bargaining implies

$$
\begin{gathered}
-\frac{\frac{\partial\left(v_{t}^{l o}-v_{t}^{u}\right)}{\partial h_{t}^{o}}}{\frac{\partial v_{t}^{e a}}{\partial h_{t}^{o}}}=(1-\theta) \frac{\left(v_{t}^{l o}-v_{t}^{u}\right)}{\theta\left(v_{t}^{e a}\right)} \\
-\frac{\left(\frac{\partial\left(v_{t}^{l o}-v_{t}^{u}\right)}{\partial w_{t}^{o}}\right)}{\frac{\partial v_{t}^{e a}}{\partial w_{t}^{o}}}=\frac{\partial v_{t}^{e a}}{\partial w_{t}^{o}}(1-\theta) \frac{\left(v_{t}^{l o}-v_{t}^{u}\right)}{\theta\left(v_{t}^{e a}\right)}
\end{gathered}
$$

that is:

$$
\frac{\frac{\partial\left(v_{t}^{l o}-v_{t}^{u}\right)}{\partial h_{t}^{o}}}{\frac{\partial v_{t}^{e a}}{\partial h_{t}^{o}}}=\frac{\left(\frac{\partial\left(v_{t}^{l o}-v_{t}^{u}\right)}{\partial w_{t}^{o}}\right)}{\frac{\partial v_{t}^{e a}}{\partial w_{t}^{o}}}
$$

\section{A.1.3 Banks}

Official banks lend funds to official wholesale firms, who use them to purchase capital goods. There is an exogenous probability $\sigma_{(1-l)}$ that bankers continue to perform their role in the following period. In turn, with probability $\left(1-\sigma_{(1-l)}\right)$ bankers exit the financial sector and become workers; therefore for each individual engaged in banking, activity is expected to last $\left(1-\sigma_{(1-l)}\right)^{-1}$ periods. $^{20}$ Exiting bankers transfer their net worth to the household. The household provides new bankers with an initial endowment which is a fraction $\rho_{(1-l)}\left(1-\sigma_{(1-l)}\right)^{-1}$ of last period loans.

At the end of period $t$ the $j$ - $t h$ banker's balance sheet is given by:

$$
q_{t}^{o} L_{j, t}^{W}=\left(D_{j, t+1}+N W_{j, t}\right)\left(\frac{p_{t}^{o}}{p_{t}}\right)
$$


where $L_{j, t}^{W}$ is the amount of claims on firms, $q_{t}^{o}$ is their relative price in terms of the consumption bundle (A.3), and $N W_{j, t}$ is the banker net worth at the end of period $t$. Bankers' net worth and bank deposits are defined in official goods, whose relative price price in terms of the consumption bundle is $\frac{p^{o}}{p}$.

The banker charges a gross return $R_{t}^{W}$ on loans, and pays a gross real return $R_{t-1}^{D}$ on households deposits. A credit spread arises as difference between earnings on assets and interests paid on liabilities in presence of imperfect capital market: the banker will only fund projects with an expected return of no less than the discounted cost of borrowing. Assuming that the discount factor of the banker between time $t$ and $t+i$ is the household's intertemporal marginal rate of substitution, the following participation constraint must hold:

$$
E_{t} \beta \frac{\pi_{t+i}^{R, o} \lambda_{t+i}}{\pi_{t+i} \lambda_{t}}\left(R_{t+i+1}^{W}-R_{t+i}^{D}\right) \geq 0 \quad i \geq 0
$$

So the banker accumulates wealth until he exits the market.

The evolution of the banker's real net worth is:

$$
N W_{j, t+1}=\left(R_{t}^{W}-R_{t-1}^{D}\right) \frac{q_{t}^{o}}{\left(\frac{p_{t}^{o}}{p_{t}}\right)} L_{j, t}^{W}+R_{t-1}^{D} N W_{j, t}
$$

A credit spread arises as difference between earnings on assets and interests paid on liabilities in presence of imperfect capital market: the banker will only fund projects with an expected return of no less than the discounted cost of borrowing. Assuming that the discount factor of the banker between time $t$ and $t+i$ is the household's intertemporal marginal rate of substitution, the following participation constraint must hold:

$$
E_{t} \beta \frac{\pi_{t+i}^{R, o} \lambda_{t+i}}{\pi_{t+i} \lambda_{t}}\left(R_{t+i+1}^{W}-R_{t+i}^{D}\right) \geq 0 \quad i \geq 0
$$

So the banker accumulates wealth until he exits the market. Therefore he will maximize the discounted value of expected terminal wealth, $V_{j, t}$.

$V_{j, t}=E_{t} \sum_{i=0}^{\infty}\left(1-\sigma_{(1-h)}\right) \sigma_{(1-h)} \beta^{i+1} \frac{\pi_{t+i+1}^{R, o} \lambda_{t+i+1}}{\pi_{t+i+1} \lambda_{t+i}}\left[\left(R_{t+i}^{W}-R_{t+i-1}^{D}\right) \frac{q_{t+i}^{o}}{\left(\frac{p_{t+i}^{o}}{p_{t+i}}\right)} L_{j, t+i}^{W}+R_{t+i-1}^{D} N W_{j, t+i}\right]$

At the beginning of each period the banker may choose to divert a fraction $\phi$ 
of available funds from the bank portfolio because, by assumption, $\phi$ defines the unit cost households must bear to recover diverted funds. To ensure that depositors are willing to supply funds to bankers the following incentive constraint must be satisfied:

$$
V_{j, t} \geq \phi \frac{q_{t}^{o}}{\left(\frac{p_{t}^{o}}{p_{t}}\right)} L_{j, t}^{W}
$$

i.e. the discounted value of expected terminal wealth $V_{j, t}$ should not be less than the value of divertible funds.

Following Gertler and Karadi (2011) the present discounted value of net worth at the end of the period takes the following form:

$$
\begin{aligned}
& V_{j, t}=v_{j, t}^{k} \frac{q_{t}^{o}}{\left(\frac{p_{t}^{o}}{p_{t}}\right)} L_{j, t}^{W}+\eta_{j, t} N W_{j, t} \\
& \eta_{j, t}=E_{t}\left\{\left(1-\sigma_{(1-l)}\right)+\beta \frac{\pi_{t+1}^{R, o} \lambda_{t+1}}{\pi_{t+1} \lambda_{t}} \sigma_{(1-l)} \eta_{j, t+1} \frac{N W_{j, t+1}}{N W_{j, t}}\right\}
\end{aligned}
$$

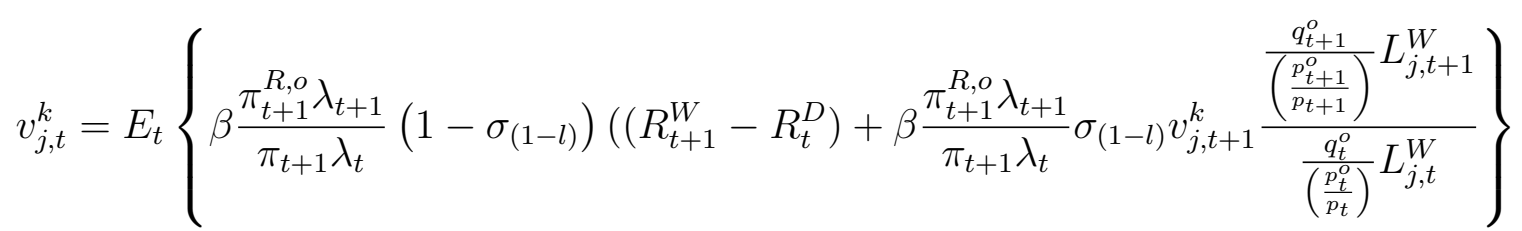

where $v_{t}^{k}$ is the expected discounted marginal gain to the banker of expanding nonfinancial claims by a unit (keeping net worth constant), $\eta_{t}$ defines the expected discounted value of having another unit of net worth (holding assets constant) and the banker's leverage ratio

$$
l e v_{j, t}=\frac{\eta_{j, t}}{\phi-v_{j, t}^{k}}
$$

limits the banker's access to households deposits, so that the incentive constraint (A.18) is satisfied. Summing across the portfolios of each individual bank in the market we obtain the relationship between the outstanding stock of loans and the aggregate net worth of banks

$$
\frac{q_{t}^{o}}{\left(\frac{p_{t}^{o}}{p_{t}}\right)} L_{t}^{W}=l e v_{t} N W_{t}
$$

The net worth of existing bankers, $N W_{t}^{e}$, evolves according to:

$$
N W_{t}^{e}=\sigma_{(1-l)}\left\{\left(R_{t}^{W}-R_{t-1}^{D}\right) l e v_{t-1}+R_{t-1}^{D}\right\} N W_{t-1}^{e}
$$


New born-bankers are endowed with $\frac{\varrho_{(1-l)}}{\left(1-\sigma_{(1-l)}\right)} L_{t-1}^{W}$. Hence, the law of motion of the total net worth is:

$$
N W_{t}=\sigma_{(1-l)}\left\{\left(\left(R_{t}^{W}-R_{t-1}^{D}\right) l e v_{t-1}+R_{t-1}^{D}\right\} \frac{N W_{t-1}}{\exp \left(\xi_{t}^{o}\right)}+\varrho_{(1-l)} q_{t-1}^{o} L_{t-1}^{W}\right.
$$

where $\xi_{t}^{o}$ defines a i.i.d. net worth shock, as in Gertler and Karadi (2011).

\section{A.1.4 Firms}

In each sector $j(o, s)$, perfectly competitive (flex-price) firms produce wholesale (intermediate) goods $I^{W, j}$ and sell them to retail producers $R, j$ that differentiate products and are subject to price adjustment costs.

\section{A.1.4.1 Wholesale producers}

Wholesale producers have access to the production technology:

$$
y_{t}^{j}=\left(k_{t-1}^{j}\right)^{\alpha^{j}}\left(h_{t}^{j} l_{t}^{j}\right)^{1-\alpha^{j}}
$$

where $y_{t}^{j}, k_{t}^{j}, h_{t}^{j}$ respectively define sector-specific output, capital and labor inputs.

Informal firms As discussed above, informal firms hire factor inputs directly from households. Their factor demands are:

$$
w_{t}^{s}=\left(1-\alpha^{s}\right)\left(\frac{k_{t-1}^{s}}{h_{t}^{s} l_{t}^{s}}\right)^{\alpha^{s}}
$$

and

$$
r_{t}^{k, s}=\alpha^{s}\left(\frac{k_{t-1}^{s}}{h_{t}^{s} l_{t}^{s}}\right)^{-\left(\alpha^{s}-1\right)} .
$$

Intermediate goods are sold to final goods producers at

$$
p_{t}^{I^{W}, s}=\left(\frac{r_{t}^{k, s}}{\alpha^{s}}\right)^{\alpha^{s}}\left(\frac{w_{t}^{s}}{\left(1-\alpha^{s}\right)}\right)^{1-\alpha^{s}}
$$

where $p_{t}^{I^{W}, s}$ defines the price of informal intermediate goods in terms of the informal retail price. 
Official firms and capital goods producers At the beginning of each period official firms use funds borrowed from banks to finance their capital acquisition from capital goods producers to be used for production. After production, undepreciated capital is sold back to capital goods producers. Their profits in terms of the consumption bundle are

$$
\Pi_{t}^{I^{W}, o}=y_{t}^{o} \frac{p_{t}^{I^{W}, o}}{p_{t}}+q_{t}^{o}(1-\delta) k_{t-1}^{o}-R_{t}^{W} q_{t-1}^{o} k_{t-1}^{o}-\frac{p_{t}^{I^{W}, o}}{P_{t}} P_{t}^{E A W} h_{t}^{o} l_{t}^{o}
$$

Intermediate firms' capital demand is such that

$$
\frac{\left\{r_{t}^{k, o}\left(\frac{p_{t}^{I^{W}, o}}{p_{t}}\right)+q_{t}^{o}(1-\delta)\right\}}{q_{t-1}^{o}}=R_{t}^{W}
$$

where $r_{t}^{k, o}=\alpha^{o} \theta_{t}^{o}\left(\frac{k_{t-1}^{o}}{\left.h_{t}^{o l}\right)_{t}}\right)^{-\left(\alpha^{o}-1\right)}$ defines the marginal productivity of capital. Demand for the labor bundle is

$$
P_{t}^{E A W}=\left(1-\alpha^{o}\right)\left(\frac{k_{t-1}^{o}}{h_{t}^{o} l_{t}^{o}}\right)^{\alpha^{o}}
$$

Official intermediate goods are sold to final goods producers at

$$
p_{t}^{I^{W}, o}=\left(\frac{r_{t}^{k, o}}{\alpha^{o}}\right)^{\alpha^{o}}\left(\frac{P_{t}^{E A W}}{\left(1-\alpha^{o}\right)}\right)^{1-\alpha^{o}}
$$

At the end of each period capital goods producers purchase undepreciated capital from intermediate firms and obtain from retail firms the final goods devoted to investment in order to assemble the capital goods which are then sold to the wholesale firms. Capital accumulation is subject to:

$$
k_{t}^{o}=(1-\delta) k_{t-1}^{o}+\left[1-S\left(\frac{I_{t}^{o}}{I_{t-1}^{o}}\right)\right] I_{t}^{o}
$$

where

$$
S\left(\frac{I_{t}^{o}}{I_{t-1}^{o}}\right)=\frac{\gamma_{I}}{2}\left(\frac{I_{t}^{o}}{I_{t-1}^{o}}-1\right)^{2}
$$

defines investment adjustment costs. 
Their expected discounted profits in terms of the consumption bundle are:

$$
E_{t} \sum_{i=0}^{\infty} \beta^{i} \frac{\lambda_{t+i}}{\lambda_{t}}\left[q_{t}^{o} k_{t}^{o}-q_{t}^{o}(1-\delta) k_{t-1}^{o}-\frac{p_{t}^{I^{W}, o}}{p_{t}} I_{t}^{o}\right]
$$

and the first order condition for their maximization problem is:

$$
\begin{aligned}
\frac{p_{t}^{I^{W}, o}}{p_{t}}= & q_{t}^{o}\left\{1-\gamma_{I}\left(\frac{I_{t}^{o}}{I_{t-1}^{o}}-1\right) \frac{I_{t}^{o}}{I_{t-1}^{o}}-\frac{\gamma_{I}}{2}\left(\frac{I_{t}^{o}}{I_{t-1}^{o}}-1\right)^{2}\right\} \\
& +\beta \frac{\lambda_{t+1}}{\lambda_{t}} q_{t+1}^{o} \gamma_{I}\left(\frac{I_{t+1}^{o}}{I_{t}^{o}}-1\right)\left(\frac{I_{t+1}^{o}}{I_{t}^{o}}\right)^{2}
\end{aligned}
$$

\section{A.1.4.2 Retail producers}

Retail producers turn intermediate goods into differentiated retail products. We assume a sticky price specification based on Rotemberg (1982) quadratic cost of nominal price adjustment:

$$
\frac{\varphi}{2}\left(\pi_{t}^{R j}-1\right)^{2}
$$

where $\varphi \geq 0$ is a measure of price stickiness, $\pi_{t}^{R j}=\frac{P_{t}^{R j}}{P_{t-1}^{R j}}$ denotes the sectoral gross inflation rate.

In a symmetrical equilibrium the price adjustment rule satisfies:

$$
\begin{aligned}
\left(\frac{\left(1-\sigma^{j}\right)}{\sigma^{j}}+p_{t}^{I^{W}, j}\right) \frac{\sigma^{j}}{\varphi}+\beta \frac{\pi_{t+1}^{j} \lambda_{t+1}}{\pi_{t+1} \lambda_{t}} \frac{y_{t+1}^{j}}{y_{t}^{j}}\left[\left(\pi_{t+1}^{R j}-1\right)\left(\pi_{t+1}^{R j}\right)\right] & \\
= & \left(\pi_{t}^{R j}-1\right) \pi_{t}^{R j}
\end{aligned}
$$

the sectoral price index is determined as

$$
P_{t}^{R, j}=P_{t-1}^{R, j} \pi_{t}^{R j}
$$

The inflation rate for the price index of the price index of the consumption bundle (A.4) is:

$$
\pi_{t}=\frac{P_{t}}{P_{t-1}}
$$




\section{A.1.5 Market clearing}

$$
\begin{gathered}
y_{t}^{o}=c_{t}^{o}+I_{t}^{o}+\frac{\varphi}{2} y_{t}^{o}\left(\pi_{t}^{R, o}-1\right)^{2}+f_{p v}^{E A} V_{t} \\
y_{t}^{s}=c_{t}^{s}+I_{t}^{s}+\frac{\varphi}{2} y_{t}^{s}\left(\pi_{t}^{s}-1\right)^{2}
\end{gathered}
$$

\section{A.1.6 Labor resource constraint}

The labor resource constraint is:

$$
l=l_{t}^{o}+l_{t}^{s}+u_{t}
$$

\section{A.1.7 Monetary policy rule}

Monetary policy is assumed to follow a standard inflation-targeting rule with interestrate smoothing, where $i$ defines the steady state nominal interest rate

$$
i_{t}=\left[i\left(\pi_{t}^{o}\right)^{\phi_{\pi}}\right]^{\rho_{i}}\left[i_{t-1}\right]^{1-\rho_{i}}
$$

and the link between the nominal and the real interest rates is given by a standard Fisher equation:

$$
1+i_{t}=R_{t}^{D} E_{t} \pi_{t+1}^{o}
$$

\section{A.1.8 Calibration}

The agency problem in the banking sector is parameterized as in Gertler and Karadi (2011). The fraction of funds that can be diverted, $\phi$, is set at 0.381 : the survival rate of banker, $\sigma_{(1-l)}$, is 0.975 , the proportional transfer to new bankers, $\varrho_{(1-l)}$, is 0.002 . These values allow to obtain in steady state a spread of one hundred basis points, a leverage ratio of 4 and 10 years as the average horizon for bankers.

Parameters characterizing the official economy and households preferences are fairly standard. The values chosen for the household subjective discount factor, $\beta=0.99$, the capital income share $\alpha^{o}=0.34$, the capital depreciation rate, $\delta=0.02$, follow the literature (see Fernández and Meza, 2015). The consumption habits parameter $b=0.6$ falls in the range considered in Dennis (2009). The degree of price stickiness, $\varphi=120$ is taken from Ozkan and Unsal (2012), ${ }^{21}$ to the best of our knowledge, there is no evidence about nominal rigidities in the unofficial sector. We there- 
fore take as benchmark the values adopted for the degree of price stickiness in the official sector. The price-elasticity parameter $\sigma^{o}=6$ is taken from Schmitt-Grohe and Uribe (2004). The elasticity of substitution between official and informal consumption bundles, is set at 5, similarly to Epstein and Finkelstein Shapiro (2017). Turning to firms operating in the informal economy, to capture the relatively low capital intensity in their production function we have chosen the capital share parameter, $\alpha^{s}=0.28$, as in Koreshkova (2006); we have also assumed that firms operating in the unofficial retail sector have limited market power, $\sigma^{s}=20$. The steadystate relative capital labor ratio $\frac{k^{o} / h^{o} l^{o}}{k^{s} / h^{s} l^{s}}$ is 1.58 . Parameters $\phi_{\pi}=1.5, \rho_{i}=0.9$ characterize the monetary policy rule.

Labor market parameters are selected as follows. Hobijn and Sahin (2009) find that monthly separation rates range between 2 and $0.7 \%$. We therefore set $\rho^{s}=0.96$, implying a $4 \%$ quarterly separation rate. We calibrate $m, f_{p v}^{E A}$ to obtain a job finding rate $^{22} z^{u n}=0.7$ and a vacancy filling rate $z^{V}=0.9$, as in Colgiago and Rossi (2014). ${ }^{23}$ These values are also broadly in line with the calibration in Boz, Durdu, and Li (2015) who refer to the Mexican economy. We set $b^{u}=0.5 w^{o}$ as in Bosch and Esteban-Pretel (2015). The Nash bargaining parameter $\vartheta$ is assigned value 0.5 , which is standard in this literature. Parameter $\varkappa$ in (A.8) also takes the standard value of 0.5.

Finally we close the model by calibrating $\alpha_{c}$ in order to set the steady state value of the informal economy relative size, $\frac{y^{s}}{y^{\circ}}$. Schneider and Buehn (2007) document the large dispersion of this ratio across different countries, where developing countries are typically characterized by a relatively large share of the informal economy. Following Colombo, Onnis, and Tirelli (2016) we have therefore chosen two "representative" calibrations. By setting $\frac{y^{s}}{y^{\circ}}=8 \%$ we match the sample average for advanced economies whereas $\frac{y^{s}}{y^{o}}=40 \%$ is a value common to several low income countries, Correspondingly the ratios $\frac{l^{s}}{l^{\circ}}$ are $12 \%$ and $58 \%$. We calibrate two values of $\chi(1.7$ and 1.8) in (A.1) to obtain in both steady state hours $h^{o}=1, h^{s}=0.9974$. Table A.1 summarizes all the parameters values.

\section{A.2 Empirical analysis}

GDP and investment are taken from the World Bank WDI (both are in real terms PPP adjusted). Regarding labor market data, it is well known that reasonably long crosscountry comparable time series of labor market variables are limited to advanced 
Table A.1: Parameter values

\begin{tabular}{l|l|l}
\hline Parameter & Value & Description \\
\hline \hline$\beta$ & 0.99 & Household subjective discount factor \\
\hline$\sigma^{o}$ & 6 & price-elasticity of demand for a differentiated good, official \\
\hline$\sigma^{s}$ & 20 & price-elasticity of demand for a differentiated good, informal \\
\hline$\varphi^{o}, \varphi^{s}$ & 120 & degree of price stickiness \\
\hline$\alpha^{o}$ & 0.34 & capital income share \\
\hline$\alpha^{s}$ & 0.28 & capital income share \\
\hline$\delta$ & 0.02 & depreciation rate \\
\hline$\sigma(1-l)$ & 0.975 & Banker's survival rate \\
\hline$\phi$ & 0.381 & Fraction of divertible funds \\
\hline$\varepsilon$ & 5 & $\begin{array}{l}\text { elasticity of substitution between official and informal con- } \\
\text { sumption bundles }\end{array}$ \\
\hline$\rho^{\chi}$ & 0.3 & financial shock autocorrelation \\
\hline$\rho^{s}$ & 0.96 & Survival probability of a match \\
\hline$\phi^{\pi}$ & 1.5 & Taylor parameter \\
\hline$b$ & 0.6 & External habit parameter \\
\hline$\vartheta$ & 0.5 & Nash bargaining parameter \\
\hline$\varkappa$ & 0.5 & Matching technology parameter \\
\hline$z^{u n}$ & 0.7 & Job finding rate \\
\hline$z^{V}$ & 0.9 & Vacancy filling rate \\
\hline$\rho_{i}$ & 0.9 & Monetary policy persistence parameter \\
\hline
\end{tabular}

economies. To maximize coverage we used two different data set. The first one is the recently released KILM dataset by the ILO. Its main advantage is the width of the coverage including 170 countries; the disadvantage is the depth of the time series available as observations start only from 1990. The ILO dataset is also the basis of data on the participation rate included in the World Bank WDI. The second one is taken from the OECD labor market statistics which are available only for OECD countries but for most countries to go back to 1970 .

The ILO-KILM dataset has collected and organized available estimates on informal employment, measured through surveys either at household or at establishment level. Information is however scattered as only for few countries such estimates are available and in several cases a there is not a proper time series but few isolated observations. This dataset does not lend itself to a proper econometric analysis. We have used it for the descriptive statistics in the introduction considering only countries for which a sufficient time series was available around episodes of banking crises.

An alternative approach to measuring informal employment follows Loayza and Rigolini (2011) which use as a proxy the percentage of the active labor force that is 
self-employed. As pointed out in La Porta and Shleifer (2008) the definition of selfemployment does not include unpaid family workers whose contribution to informal production is probably high. Further, it is quite obvious that self-employment can be high for structural reasons which are not related to the informal economy. By contrast, the cyclical evolution of the self-employed workers' share is likely to exhibit a strong correlation with the informal economy share, even though it does not account for intensive margin effects. Data on self employment are derived from the ILO and the World Bank (WDI) and are available for a large panel of countries starting from 1980.

In order to provide a more complete picture of the informal economy we include measures of informal economic activity. It is well known that there is not a direct way of measuring the size of the informal economy; all estimation attempts need to follow an indirect approach. We use three different measures.

- The Multiple Indicator-Multiple Cause (MIMIC) approach by Medina and Schneider (2018) which is essentially a structural model where the shadow economy is estimated from a system of equations composed of economic and institutional variables.

- The Elgin and Oztunali (2012) approach which estimate the sie of the informal economy from a calibrated DSGE model.

- The Colombo, Onnis, and Tirelli (2016) mrasure who estimate the size of the shadow economy with the modified total electricity approach.

Tables A.3 and A.2 provide respectively the descriptive statistics for each variable and the list of countries contained in each dataset.

Data on banking crises are taken from the dataset developed by Laeven and Valencia (2010, 2008), who build on the early work by Caprio and Klingebiel (1996). More specifically Laeven and Valencia (2010) focus on systemic banking crises excluding distress events that affected isolated banks. ${ }^{24}$

\section{A.2.1 Panel stationarity tests}

The autoregressive model underlying impulse responses reported in section 2 of the paper is estimated using variables in growth rates given the trending nature of most macroeconomic variables. In this section we report the Im-Pesaran-Shin panel unit 
Table A.2: List of countries

\begin{tabular}{|c|c|c|c|c|}
\hline Afghanistan & China & Hungary & Moldova & Slovakia* \\
\hline Albania & Colombia & Iceland* & Mongolia & Slovenia* \\
\hline Algeria & Congo & India & Montenegro & South Africa \\
\hline Angola & Congo, Dem. Rep. & Indonesia & Morocco & Spain* \\
\hline Argentina & Costa Rica & Iran & Myanmar & Sri Lanka \\
\hline Armenia & Croatia & Iraq & Namibia & Sudan \\
\hline Australia* & Cyprus & Ireland* & Nepal & Suriname \\
\hline Austria* & Czech Republic* & Israel* $^{*}$ & Netherlands* & Swaziland \\
\hline Azerbaijan & Cte d'Ivoire & Italy* & New Caledonia & Sweden* \\
\hline Bahamas & Denmark* & Jamaica & New Zealand* & Switzerland* \\
\hline Bahrain & Djibouti & Japan* & Nicaragua & Syria \\
\hline Bangladesh & Dominican Rep. & Kazakhstan & Niger & Tajikistan \\
\hline Barbados & Ecuador & Kenya & Nigeria & Tanzania \\
\hline Belarus & Egypt & Korea* & Norway* & Thailand \\
\hline Belgium* & El Salvador & Kuwait & Oman & Togo \\
\hline Belize & Estonia* & Kyrgyzstan & Pakistan & Tonga \\
\hline Benin & Ethiopia & Latvia* & Panama & Trinidad Tob. \\
\hline Bhutan & Fiji & Lebanon & Papua New G. & Tunisia \\
\hline Bolivia & Finland* & Lesotho & Paraguay & Turkey* \\
\hline Bosnia Herz. & France* & Liberia & Peru & Uganda \\
\hline Botswana & French Guiana & Libya & Philippines & Ukraine \\
\hline Brazil & Georgia & Lithuania & Poland* & United Arab Emirates \\
\hline Brunei Darussalam & Germany* & Luxembourg* & Portugal* & United Kingdom* \\
\hline Bulgaria & Ghana & Macau & Qatar & United States* \\
\hline Burkina Faso & Greece* & Madagascar & Romania & Uruguay \\
\hline Burundi & Guadeloupe & Malawi & Russian & Uzbekistan \\
\hline Cambodia & Guatemala & Malaysia & Rwanda & Venezuela \\
\hline Cameroon & Guinea & Mali & Saint Lucia & Vietnam \\
\hline Canada* & Guinea-Bissau & Malta & Saudi Arabia & Yemen \\
\hline Cape Verde & Guyana & Martinique & Senegal & Zambia \\
\hline Central African Rep. & Haiti & Mauritania & Serbia & Zimbabwe \\
\hline Chad & Honduras* & Mauritius & Sierra Leone & \\
\hline Chile* & Hong Kong & Mexico* & Singapore & \\
\hline
\end{tabular}

Note: ${ }^{*}$ denotes countries included in the OECD dataset 
Table A.3: Summary statistics

\begin{tabular}{lllll}
\hline Variable & Obs & Mean & Std.Dev. & Source \\
Participation rate & 4368 & 62.73 & 9.99 & KILM \\
Employment rate & 4200 & 57.21 & 11.64 & KILM \\
Unemployment rate & 5040 & 9.24 & 7.16 & KILM \\
Participation rate & 1165 & 60.58 & 6.93 & OECD \\
Employment rate & 1178 & 64.89 & 7.95 & OECD \\
Unemployment rate & 1165 & 7.37 & 4.13 & OECD \\
Self employment share & 2142 & 27.10 & 17.11 & WB/ILO \\
GDP growth & 7241 & 3.72 & 5.76 & WB \\
Investment growth & 4901 & 5.03 & 15.81 & WB \\
Share shadow & 3775 & 31.51 & 12.88 & Scheider \\
Share shadow & 5360 & 34.48 & 13.53 & Elgin Oztunali \\
Share shadow & 3025 & 25.37 & 17.27 & Colombo, Onnis, Tirelli \\
\hline
\end{tabular}

Table A.4: Panel stationarity test

\begin{tabular}{lcc}
\hline Variable & Level & Growth \\
\hline \hline Participation rate (Kilm) & 4.200 & $-20.451^{* * *}$ \\
Unemployment rate (Kilm) & -0.209 & $-31.510^{* * *}$ \\
Participation rate (OECD) & -0.912 & $-15.556^{* * *}$ \\
Unemployment rate (OECD) & 0.316 & $-12.159^{* * *}$ \\
Share self employed & 1.068 & $-16.469^{* * *}$ \\
\hline
\end{tabular}

root test we have conducted on the data. table A.4 reports the results. The first column refers to the level of the variable, the second one to its growth rate. In all cases we cannot reject the null of non stationarity in levels, while we always reject it in growth rates.

\section{A.2.2 Regression results}

This section contains the tables from the regression results used to generate the impulse responses of section 2 and present the instrument validity tests. All regressions implement the Blundell and Bond (1998) system GMM estimator; robust standard errors apply Windmeijer's finite sample correction.

It is well known that in dynamic panel data the use of lagged values of the endogenous and exogenous variable for orthogonbality conditions results in a proliferation of instrument which weakens the Hansen test of the instruments' joint validity. In order to deal with this problem we collapse the instruments as suggested by Roodman (2009). In all the cases the Hansen test, cannot reject the null hypoth- 
esis that the full set of orthogonality conditions is valid. The Arellano-Bond test for autocorrelation rejects the null hypothesis of first order serial correlation and does not reject the null of no second-order serial correlation in the first-differenced error terms.

Overall the tests suggest that the instruments used are valid and that the error correlation is of no concern.

Table A.5: GDP, investment and financial crises

\begin{tabular}{lcccccc}
\hline \hline & & GDP & & \multicolumn{3}{c}{ Investment } \\
& $\mathrm{S} 1$ & $\mathrm{~S} 2$ & $\mathrm{~S} 3$ & $\mathrm{~S} 1$ & $\mathrm{~S} 2$ & $\mathrm{~S} 3$ \\
\hline Dep. var. L1 & $0.335^{* * *}$ & $0.329^{* * *}$ & $0.332^{* * *}$ & $0.213^{* * *}$ & $0.307^{* * *}$ & $0.198^{* * *}$ \\
& $(0.029)$ & $(0.093)$ & $(0.030)$ & $(0.038)$ & $(0.057)$ & $(0.039)$ \\
Dep .var. L2 & $0.041^{*}$ & -0.028 & $0.044^{*}$ & -0.003 & 0.023 & -0.009 \\
& $(0.022)$ & $(0.051)$ & $(0.023)$ & $(0.026)$ & $(0.039)$ & $(0.027)$ \\
Dep. var. L3 & $0.043^{* *}$ & $0.075^{*}$ & $0.041^{*}$ & 0.037 & -0.025 & 0.037 \\
& $(0.021)$ & $(0.044)$ & $(0.022)$ & $(0.030)$ & $(0.045)$ & $(0.031)$ \\
Crisis & $-0.015^{* * *}$ & $-0.016^{* *}$ & $-0.014^{* *}$ & $-0.061^{* * *}$ & $-0.034^{* *}$ & $-0.065^{* * *}$ \\
& $(0.005)$ & $(0.007)$ & $(0.006)$ & $(0.018)$ & $(0.014)$ & $(0.023)$ \\
Crisis L1 & $-0.024^{* * *}$ & $-0.038^{* * *}$ & $-0.020^{* * *}$ & $-0.113^{* * *}$ & $-0.089^{* * *}$ & $-0.107^{* * *}$ \\
& $(0.006)$ & $(0.007)$ & $(0.008)$ & $(0.019)$ & $(0.011)$ & $(0.024)$ \\
Crisis L2 & 0.006 & 0.005 & 0.008 & 0.002 & $-0.033^{*}$ & 0.017 \\
& $(0.005)$ & $(0.008)$ & $(0.006)$ & $(0.017)$ & $(0.018)$ & $(0.020)$ \\
Crisis L3 & 0.002 & 0.003 & 0.003 & $0.032^{*}$ & $0.021^{*}$ & $0.037^{*}$ \\
& $(0.005)$ & $(0.004)$ & $(0.006)$ & $(0.017)$ & $(0.012)$ & $(0.021)$ \\
\hline N. Obs & 6453 & 1020 & 5433 & 4275 & 991 & 3284 \\
N. Countries & 191 & 25 & 166 & 157 & 24 & 133 \\
\hline \hline
\end{tabular}

Note: system GMM OLS estimates, robust standard errors in brackets, Windmeijer finite sample correction applied, collapsed instruments. Time dummies included but not reported. * denotes significance at 0.1 level, ${ }^{* *}$ at $0.05,{ }^{* *}$ at 0.01 . S1, 2, 3 denote respectively All countries, High income countries and Non high income countries

\section{A.2.3 Robustness checks}

The analyses developed in section 2 of the paper and in the previous section look at the relationship between banking crises and each variable separately, neglecting that macroeconomic variables are jointly determined in equilibrium. In order to shed light on this issue we have analyzed the joint response of the participation rate and GDP following a banking crisis. We have done so through a panel-VAR that takes into account the interrelations between the relevant variables. Residuals are orthogonalized with a Choleski decomposition that relies on variables ordering for allocating any correlation between residuals. These orderings are consistent with 
Table A.6: Employment rate and financial crises

\begin{tabular}{lccccc}
\hline \hline & & KILM & \multicolumn{2}{c}{ OECD } \\
& S1 & S2 & S3 & S1 & S2 \\
\hline & All countries & High income & Non high income & All countries & High income \\
Dep. var. L1 & 0.068 & $0.413^{* * *}$ & -0.012 & $0.475^{* * *}$ & $0.467^{* * *}$ \\
& $(0.042)$ & $(0.068)$ & $(0.044)$ & $(0.066)$ & $(0.060)$ \\
Dep .var. L2 & 0.007 & -0.016 & -0.022 & -0.025 & -0.028 \\
& $(0.031)$ & $(0.040)$ & $(0.034)$ & $(0.054)$ & $(0.056)$ \\
Dep. var. L3 & 0.006 & 0.066 & -0.006 & 0.011 & -0.005 \\
& $(0.024)$ & $(0.050)$ & $(0.025)$ & $(0.037)$ & $(0.053)$ \\
Crisis & $-0.008^{* * *}$ & $-0.005^{*}$ & $-0.009^{* *}$ & -0.005 & -0.003 \\
& $(0.003)$ & $(0.003)$ & $(0.004)$ & $(0.003)$ & $(0.004)$ \\
Crisis L1 & $-0.009^{* * *}$ & $-0.014^{* *}$ & -0.004 & $-0.024^{* * *}$ & $-0.019^{* * *}$ \\
& $(0.003)$ & $(0.006)$ & $(0.004)$ & $(0.008)$ & $(0.007)$ \\
Crisis L2 & $-0.007^{* *}$ & $-0.011^{* * *}$ & -0.004 & -0.007 & $-0.011^{* *}$ \\
& $(0.003)$ & $(0.004)$ & $(0.004)$ & $(0.005)$ & $(0.004)$ \\
Crisis L3 & 0.005 & -0.003 & $0.009^{* *}$ & 0.002 & 0.002 \\
& $(0.003)$ & $(0.004)$ & $(0.004)$ & $(0.005)$ & $(0.004)$ \\
N. Obs & 3432 & 989 & 2443 & 1039 & 796 \\
N. Countries & 168 & 49 & 119 & 35 & 23 \\
\hline \hline
\end{tabular}

Note: system GMM OLS estimates, robust standard errors in brackets, Windmeijer finite sample correction applied, collapsed instruments. Time dummies included but not reported. ${ }^{*}$ denotes significance at 0.1 level, ${ }^{* *}$ at $0.05,{ }^{* *}$ at 0.01 . S1, 2, 3 denote respectively All countries, High income countries and Non high income countries 
Table A.7: Unemployment rate and financial crises

\begin{tabular}{lccccc}
\hline \hline & \multicolumn{3}{c}{ KILM } & \multicolumn{2}{c}{ OECD } \\
& S1 & S2 & S3 & S1 & S2 \\
\hline Dep. var. L1 & -0.045 & 0.027 & $-0.146^{* * *}$ & $0.437^{* * *}$ & $0.395^{* * *}$ \\
& $(0.059)$ & $(0.079)$ & $(0.054)$ & $(0.072)$ & $(0.066)$ \\
Dep .var. L2 & -0.058 & $-0.177^{* * *}$ & $-0.072^{*}$ & -0.080 & -0.014 \\
& $(0.069)$ & $(0.041)$ & $(0.037)$ & $(0.057)$ & $(0.062)$ \\
Dep. var. L3 & 0.010 & $0.221^{* * *}$ & $-0.053^{*}$ & -0.025 & -0.032 \\
& $(0.055)$ & $(0.019)$ & $(0.029)$ & $(0.029)$ & $(0.033)$ \\
Crisis & 0.029 & 0.045 & 0.024 & 0.076 & 0.087 \\
& $(0.026)$ & $(0.043)$ & $(0.034)$ & $(0.051)$ & $(0.053)$ \\
Crisis L1 & $0.130^{* * *}$ & $0.155^{* *}$ & $0.072^{*}$ & $0.289^{* * *}$ & $0.258^{* * *}$ \\
& $(0.037)$ & $(0.066)$ & $(0.042)$ & $(0.053)$ & $(0.054)$ \\
Crisis L2 & $0.063^{* * *}$ & $0.110^{* * *}$ & 0.032 & 0.004 & 0.039 \\
& $(0.023)$ & $(0.028)$ & $(0.027)$ & $(0.036)$ & $(0.039)$ \\
Crisis L3 & -0.031 & $0.055^{*}$ & $-0.060^{* * *}$ & 0.006 & -0.024 \\
& $(0.020)$ & $(0.031)$ & $(0.021)$ & $(0.035)$ & $(0.036)$ \\
\hline N. Obs & 3432 & 989 & 2443 & 1025 & 782 \\
N. Countries & 168 & 49 & 119 & 35 & 23 \\
\hline
\end{tabular}

Note: system GMM OLS estimates, robust standard errors in brackets, Windmeijer finite sample correction applied, collapsed instruments. Time dummies included but not reported. ${ }^{*}$ denotes significance at 0.1 level, ${ }^{* *}$ at $0.05,{ }^{* *}$ at 0.01 . S1, 2, 3 denote respectively All countries, High income countries and Non high income countries

Table A.8: Participation rate and financial crises

\begin{tabular}{lccccc}
\hline \hline & \multicolumn{3}{c}{ KILM } & \multicolumn{2}{c}{ OECD } \\
& $\mathrm{S} 1$ & $\mathrm{~S} 2$ & $\mathrm{~S} 3$ & $\mathrm{~S} 1$ & $\mathrm{~S} 2$ \\
\hline Dep. var. L1 & $0.229^{* * *}$ & $0.279^{* * *}$ & $0.226^{* * *}$ & 0.076 & $0.110^{*}$ \\
& $(0.039)$ & $(0.066)$ & $(0.054)$ & $(0.052)$ & $(0.066)$ \\
Dep .var. L2 & $0.106^{* * *}$ & 0.063 & $0.104^{* * *}$ & 0.033 & 0.031 \\
& $(0.027)$ & $(0.045)$ & $(0.035)$ & $(0.043)$ & $(0.053)$ \\
Dep. var. L3 & $0.094^{* * *}$ & 0.054 & $0.078^{* *}$ & 0.010 & -0.027 \\
& $(0.026)$ & $(0.050)$ & $(0.034)$ & $(0.051)$ & $(0.055)$ \\
Crisis & $-0.004^{* * *}$ & -0.001 & $-0.004^{* *}$ & $-0.005^{* *}$ & $-0.004^{* *}$ \\
& $(0.001)$ & $(0.002)$ & $(0.002)$ & $(0.002)$ & $(0.002)$ \\
Crisis L1 & -0.001 & -0.002 & -0.000 & $-0.005^{*}$ & -0.005 \\
& $(0.002)$ & $(0.003)$ & $(0.002)$ & $(0.003)$ & $(0.003)$ \\
Crisis L2 & -0.001 & -0.003 & -0.002 & $-0.007^{* * *}$ & $-0.007^{* * *}$ \\
& $(0.002)$ & $(0.004)$ & $(0.001)$ & $(0.002)$ & $(0.002)$ \\
Crisis L3 & -0.001 & $-0.005^{*}$ & 0.001 & $-0.006^{* * *}$ & $-0.004^{* *}$ \\
& $(0.001)$ & $(0.003)$ & $(0.002)$ & $(0.002)$ & $(0.002)$ \\
\hline N. Obs & 3432 & 989 & 2443 & 1025 & 782 \\
N. Countries & 168 & 49 & 119 & 35 & 23 \\
\hline \hline
\end{tabular}

Note: system GMM OLS estimates, robust standard errors in brackets, Windmeijer finite sample correction applied, collapsed instruments. Time dummies included but not reported. ${ }^{*}$ denotes significance at 0.1 level, ${ }^{* *}$ at $0.05,{ }^{* *}$ at 0.01 . S1, 2, 3 denote respectively All countries, High income countries and Non high income countries 
Table A.9: Self employment rate and financial crises

\begin{tabular}{lccc}
\hline \hline & S1 & S2 & S3 \\
\hline Dep. var. L1 & -0.067 & $-0.107^{*}$ & -0.040 \\
& $(0.044)$ & $(0.062)$ & $(0.056)$ \\
Dep .var. L2 & $-0.159^{* * *}$ & -0.068 & $-0.153^{* * *}$ \\
& $(0.042)$ & $(0.049)$ & $(0.053)$ \\
Dep. var. L3 & -0.029 & -0.024 & 0.008 \\
& $(0.032)$ & $(0.055)$ & $(0.036)$ \\
Crisis & 0.003 & $-0.010^{*}$ & 0.016 \\
& $(0.008)$ & $(0.006)$ & $(0.015)$ \\
Crisis L1 & $0.030^{*}$ & 0.011 & 0.034 \\
& $(0.015)$ & $(0.010)$ & $(0.024)$ \\
Crisis L2 & $0.014^{*}$ & $0.013^{*}$ & $0.029^{* *}$ \\
& $(0.008)$ & $(0.007)$ & $(0.013)$ \\
Crisis L3 & 0.007 & 0.001 & 0.006 \\
& $(0.005)$ & $(0.007)$ & $(0.009)$ \\
\hline N. Obs & 1563 & 682 & 881 \\
N. Countries & 97 & 26 & 71 \\
\hline
\end{tabular}

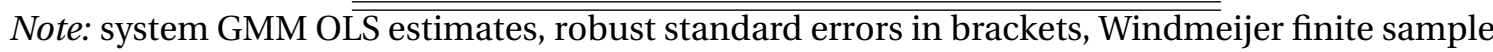
correction applied, collapsed instruments. Time dummies included but not reported. * denotes significance at 0.1 level, ${ }^{* *}$ at $0.05,{ }^{* *}$ at 0.01 . S1, 2, 3 denote respectively All countries, High income countries and Non high income countries

the assumptions of the theoretical model and posit that a financial crisis affects the following variables contemporaneously, as well as with a lag, while GDP growth and the participation rate affect the previous variables only with a lag. Estimation is conducted by GMM and the panel fixed-effects are removed using forward orthogonal deviation (Abrigo and Love, 2015).

Panel-VAR analysis allows also to provide an additional robustness check. Equation (1) assumes that the crisis is a "contemporaneously exogenous" event with respect economic activity (GDP, participation rate etc.). However if crises are the result of weak economic activity, their impact would occur through the lagged effect and our results would be biased upward. Panel-VAR analysis assumes that variables affect each other only with a lag and therefore excludes the contemporaneous effect of financial crises.

The figures A.1-A.2 show a strong negative impact of financial crises on both participation rate and GDP. On the other side GDP growth has a positive impact of the participation rate. There is no sign of reverse causality with GDP growth or the participation rate effecting banking crises. ${ }^{25}$ 
Figure A.1: Panel VAR, Kilm dataset
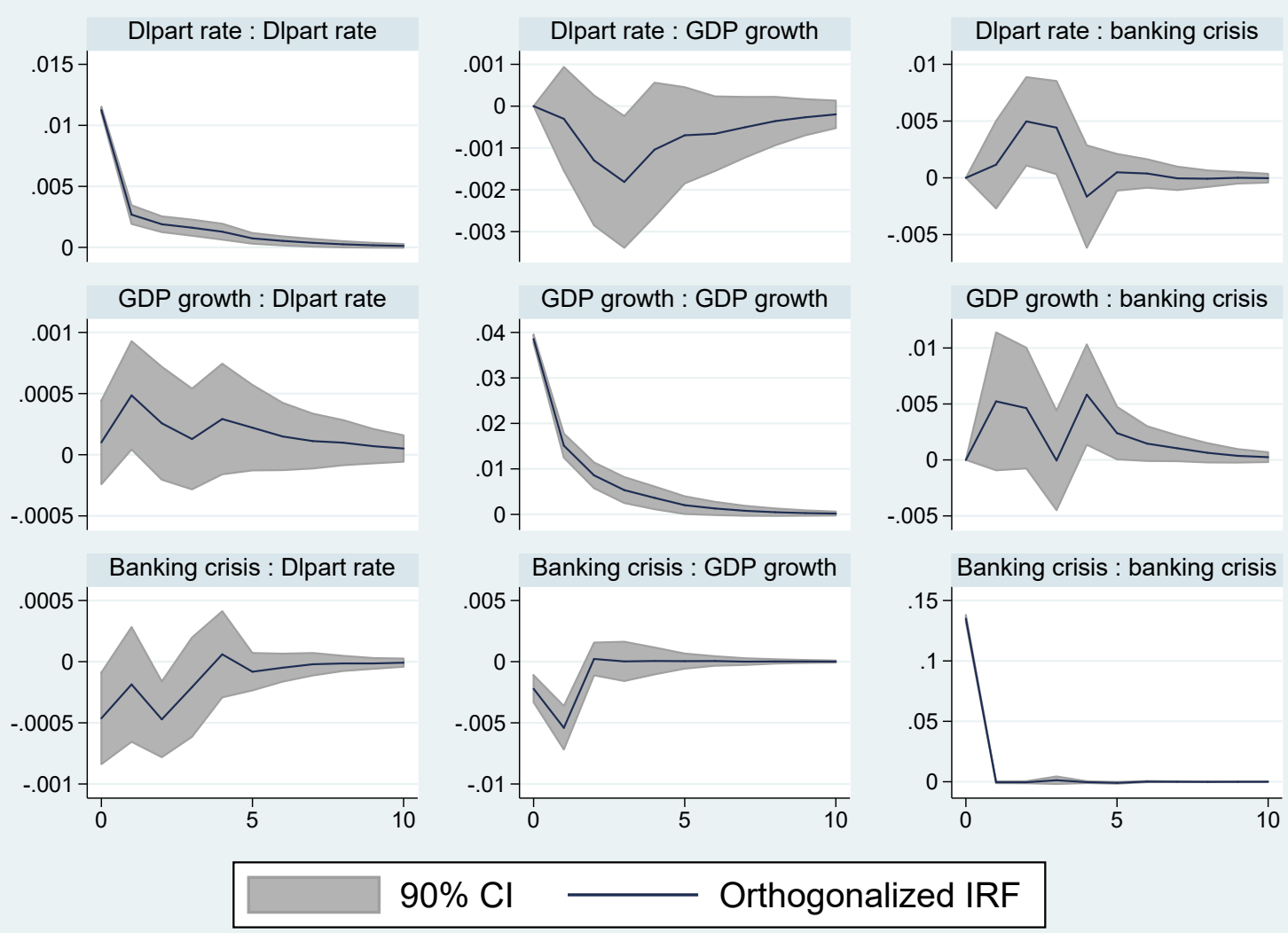
Figure A.2: Panel VAR, Oecd dataset
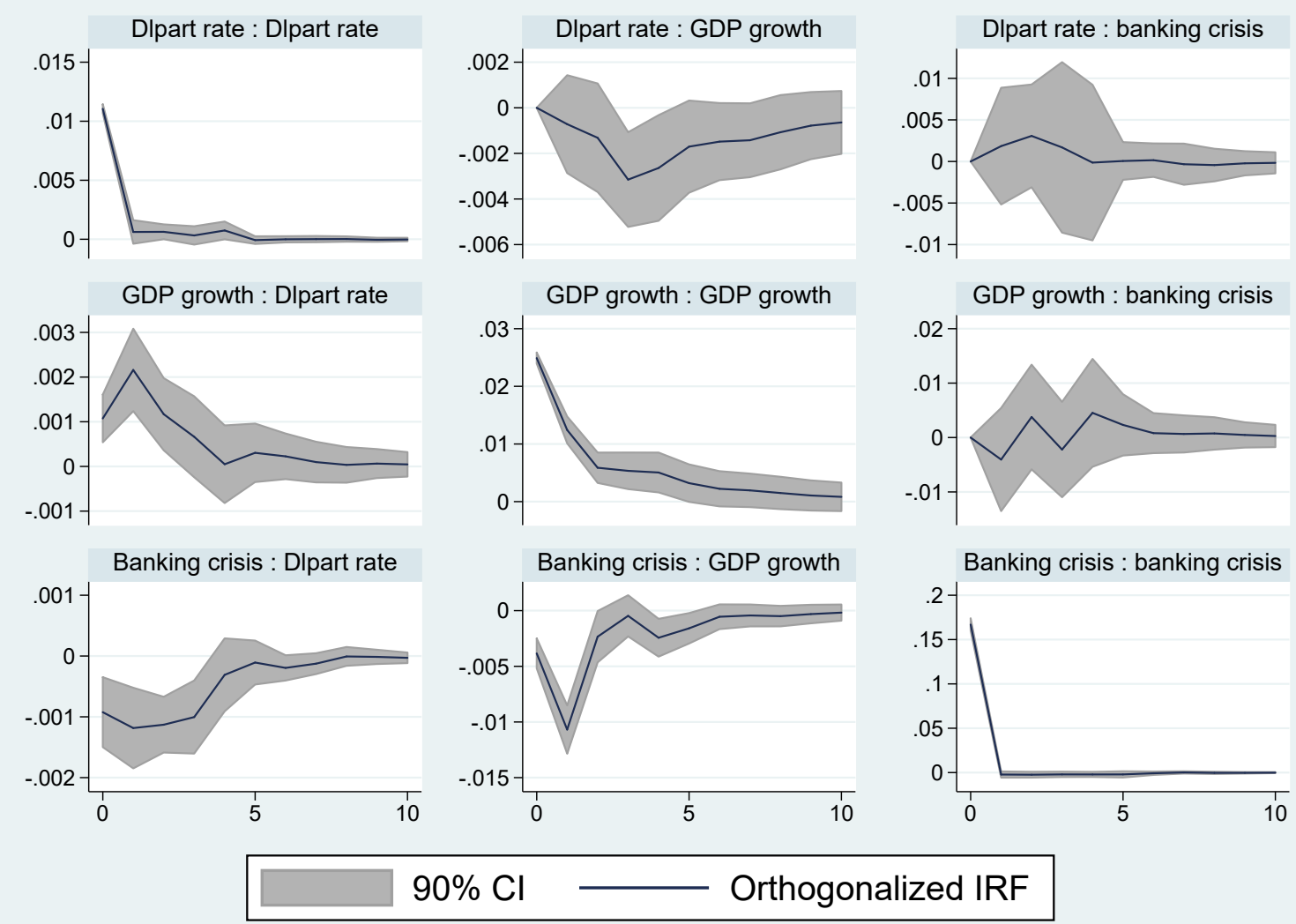


\section{Appendix References}

Abrigo, Michael R.M. and Inessa Love. 2015. "Estimation of Panel Vector Autoregression in Stata: a Package of Programs.” Mimeo, University of Hawaii.

Blundell, Richard and Stephen Bond. 1998. "Initial conditions and moment restrictions in dynamic panel data models.” Journal of Econometrics 87 (1):115-143.

Caprio, Gerard Jr. and Daniela Klingebiel. 1996. "Bank insolvencies : cross-country experience.” Policy Research Working Paper Series 1620, The World Bank.

Colombo, Emilio, Luisanna Onnis, and Patrizio Tirelli. 2016. "Shadow economies at times of banking crises: Empirics and theory." Journal of Banking \& Finance $62: 180-190$.

Elgin, Ceyhun and Oguz Oztunali. 2012. "Shadow Economies around the World: Model Based Estimates.” Working Papers 2012/05, Bogazici University, Department of Economics.

La Porta, Rafael and Andrei Shleifer. 2008. “The Unofficial Economy and Economic Development.” Brookings Papers on Economic Activity 39 (2 (Fall)):275-363.

Laeven, Luc and Fabian Valencia. 2010. "Resolution of Banking Crises: The Good, the Bad, and the Ugly.” IMF Working Papers 10/146, International Monetary Fund.

Loayza, Norman V. and Jamele Rigolini. 2011. "Informal Employment: Safety Net or Growth Engine?” World Development 39 (9):1503-1515.

Medina, Leandro and Friedrich Schneider. 2018. "Shadow economies Around the World: What Did We Learn Over the Last 20 Years?” Working Paper 18/17, IMF.

Roodman, David. 2009. "A note on the theme of too many instruments." Oxford Bulletin of Economics and Statistics 71:135-158. 